\title{
Transition Metal-Catalyzed Group Transfer Reactions for Selective C-H Bond Functionalization of Artemisinin
}

\author{
Yungen Liu, Wenbo Xiao, Man-Kin Wong, * and Chi-Ming Che* \\ Department of Chemistry, The University of Hong Kong, Pokfulam Road, Hong Kong, China. \\ cmche@hku.hk;mkwong@hkusua.hku.hk
}

\section{SUPPORTING INFORMATION}

General Experimental Section. Reagents were obtained commercially and used without further purification unless indicated otherwise. 1,2-Dichloroethane was freshly distilled from calcium hydride under a nitrogen atmosphere. Solvent was removed under reduced pressure and the residue obtained was chromatographed on a silica gel column (230 - 400 mesh) using a gradient solvent system (EtOAc/n-hexane as eluant unless specified otherwise). ${ }^{1} \mathrm{H}$ and ${ }^{13} \mathrm{C}$ NMR spectra were measured on a Bruker DPX-500, DPX-400 or DPX-300 spectrometer. Chemical shifts $(\delta$ ppm) were determined with tetramethylsilane (TMS) as internal reference. Mass spectra were determined on a Finnigan MAT 95 mass spectrometer. IR spectra were recorded on a Bio-RAD PTS-165 spectrometer. 


\section{(I) Preparation and Characterization Data of Compounds 3-22}

(3R,5aS,6R,8aS,9R,10S,12R,12aR)-10-diazoacetate, decahydro-3,6,9-trimethyl-3,12-epoxy12H-pyrano[4,3-j]-1,2-benzodioxepin-10-ol (3)

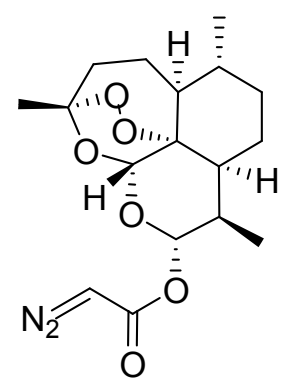

3

To a solution of DHA $(2,142 \mathrm{mg}, 0.50 \mathrm{mmol})$ and $\mathrm{Et}_{3} \mathrm{~N}(70 \mu \mathrm{L}, 0.50 \mathrm{mmol})$ in $5 \mathrm{~mL}$ of anhydrous $\mathrm{CH}_{2} \mathrm{Cl}_{2}$ at $0{ }^{\circ} \mathrm{C}$, diketene $(58 \mu \mathrm{L}, 0.75 \mathrm{mmol})$ was dropwise added. After stirring for $1 \mathrm{~h}$ at $0{ }^{\circ} \mathrm{C}$ and $2 \mathrm{~h}$ at room temperature, the reaction mixture was concentrated under reduced pressure and the resulting orange liquid was immediately dissolved in $10 \mathrm{~mL}$ of $\mathrm{CH}_{3} \mathrm{CN}$. Then, $\mathrm{Et}_{3} \mathrm{~N}(70 \mu \mathrm{L}, 0.50 \mathrm{mmol}), \mathrm{H}_{2} \mathrm{O}(10 \mu \mathrm{L}, 0.50 \mathrm{mmol})$, and $\mathrm{MsN}_{3}(56 \mu \mathrm{L}, 0.65 \mathrm{mmol})$ were added to the solution. The reaction was stirred at room temperature for $12 \mathrm{~h}$ and $\mathrm{LiOH}(24 \mathrm{mg}, 1 \mathrm{mmol})$ was added to the solution. After stirring for an additional $12 \mathrm{~h}$, the mixture was diluted with 80 $\mathrm{mL}$ of $\mathrm{Et}_{2} \mathrm{O}$ and washed successively with water and brine, dried over anhydrous $\mathrm{MgSO}_{4}$, filtered, and concentrated under reduced pressure. The residue was purified by flash column chromatography to give 3 (130 mg, $0.37 \mathrm{mmol}, 74 \%$ yield) as a pale yellow oil. ${ }^{1} \mathrm{H}$ NMR $\left(\mathrm{CDCl}_{3}\right.$, $400 \mathrm{MHz}) \delta 5.83(\mathrm{~d}, J=9.8 \mathrm{~Hz}, 1 \mathrm{H}), 5.45(\mathrm{~s}, 1 \mathrm{H}), 4.90(\mathrm{br} \mathrm{s}, 1 \mathrm{H}), 2.53(\mathrm{~m}, 1 \mathrm{H}), 2.37(\mathrm{~m}, 1 \mathrm{H})$, $2.05(\mathrm{~m}, 1 \mathrm{H}), 1.90(\mathrm{~m}, 1 \mathrm{H}), 1.82-1.68(\mathrm{~m}, 2 \mathrm{H}), 1.63(\mathrm{~m}, 1 \mathrm{H}), 1.52-1.21(\mathrm{~m}, 4 \mathrm{H}), 1.43(\mathrm{~s}, 3 \mathrm{H})$, 1.03-0.95 (m, $1 \mathrm{H}), 0.96(\mathrm{~d}, J=6.0 \mathrm{~Hz}, 3 \mathrm{H}), 0.86(\mathrm{~d}, J=7.1 \mathrm{~Hz}, 3 \mathrm{H}) ;{ }^{13} \mathrm{C} \mathrm{NMR}\left(\mathrm{CDCl}_{3}, 100\right.$ MHz) $\delta 104.48,92.13,91.48,80.11,51.55,45.24,37.24,36.20,34.06,31.82,25.93,24.55$, 
21.98, 20.19, 12.09; IR $\left(\mathrm{CH}_{2} \mathrm{Cl}_{2}\right)$ 2928, 2115, 1699, 1364, $1017 \mathrm{~cm}^{-1}$; MS (FAB) $\mathrm{m} / z 266$ ([M$\left.\left.\mathrm{CO}_{2} \mathrm{CHN}_{2}-\mathrm{H}\right]^{+}\right)$; HRMS (FAB) $\mathrm{m} / z$ for $\mathrm{C}_{15} \mathrm{H}_{22} \mathrm{O}_{4}\left(\left[\mathrm{M}-\mathrm{CO}_{2} \mathrm{CHN}_{2}-\mathrm{H}\right]^{+}\right)$; calcd 266.1518, found 266.1515 .

(3R,5aS,6R,8aS,9R,10S,12R,12aR)-10-carbamate, decahydro-3,6,9-trimethyl-3,12-epoxy12H-pyrano[4,3-j]-1,2-benzodioxepin-10-ol (4)

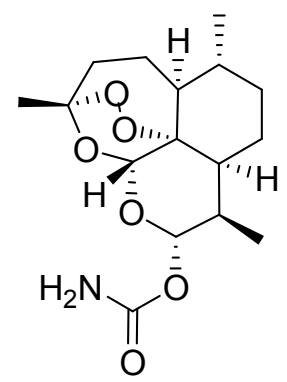

4

To a solution of DHA (3, $142 \mathrm{mg}, 0.5 \mathrm{mmol})$ in dichloromethane $(20 \mathrm{~mL})$, trichloroacetylisocyanate $(90 \mu \mathrm{L}, 0.75 \mathrm{mmol})$ was dropwise added at $0{ }^{\circ} \mathrm{C}$. After stirring for $1 \mathrm{~h}$ at $0{ }^{\circ} \mathrm{C}$ and for $15 \mathrm{~h}$ at room temperature, the reaction mixture was concentrated under reduced pressure and the resulting precipitate was dissolved in methanol $(10 \mathrm{~mL})$. Potassium carbonate (140 $\mathrm{mg}, 1.0 \mathrm{mmol}$ ) was slowly added to the solution, and the mixture was stirred for an additional $15 \mathrm{~h}$. Methanol was then evaporated under reduced pressure and the residue was purified by flash column chromatography to give $4(114 \mathrm{mg}, 0.35 \mathrm{mmol}, 70 \%)$ as a colorless oil. ${ }^{1} \mathrm{H} \mathrm{NMR}\left(\mathrm{CDCl}_{3}, 400 \mathrm{MHz}\right) \delta 5.67(\mathrm{~d}, J=9.8 \mathrm{~Hz}, 1 \mathrm{H}), 5.44(\mathrm{~s}, 1 \mathrm{H}), 5.06(\mathrm{br} \mathrm{s}, 2 \mathrm{H}), 2.52(\mathrm{~m}$, $1 \mathrm{H}), 2.37(\mathrm{~m}, 1 \mathrm{H}), 2.05(\mathrm{~m}, 1 \mathrm{H}), 1.89(\mathrm{~m}, 1 \mathrm{H}), 1.82-1.68(\mathrm{~m}, 2 \mathrm{H}), 1.63(\mathrm{~m}, 1 \mathrm{H}), 1.52-1.21$ (m, $4 \mathrm{H}), 1.42(\mathrm{~s}, 3 \mathrm{H}), 1.08-0.90(\mathrm{~m}, 1 \mathrm{H}), 0.97$ (d, $J=6.0 \mathrm{~Hz}, 3 \mathrm{H}), 0.89(\mathrm{~d}, J=7.1 \mathrm{~Hz}, 3 \mathrm{H})$; ${ }^{13} \mathrm{C}$ NMR $\left(\mathrm{CDCl}_{3}, 100 \mathrm{MHz}\right) \delta 155.30,104.48,93.16,91.41,80.20,51.54,45.28,37.30,36.23$, 34.11, 31.94, 25.99, 24.60, 22.01, 20.23, 12.12; IR $\left(\mathrm{CH}_{2} \mathrm{Cl}_{2}\right) 2930,1712,1403,1335,1010 \mathrm{~cm}^{-1}$; 
MS (EI) $m / z 266\left(\left[\mathrm{M}-\mathrm{CO}_{2} \mathrm{NH}_{2}-\mathrm{H}\right]^{+}\right)$; HRMS (EI) $m / z$ for $\mathrm{C}_{15} \mathrm{H}_{22} \mathrm{O}_{4}\left(\left[\mathrm{M}-\mathrm{CO}_{2} \mathrm{NH}_{2}-\mathrm{H}\right]^{+}\right)$; calcd 266.1518, found 266.1515.

(3R,5aS,6R,8aS,12R,12aR)-3,4,5,5a,6,7,8,8a-octahydro-3,6,9-trimethyl-3,12-epoxy-12Hpyrano[4,3-j]-1,2-benzodioxepin (5)

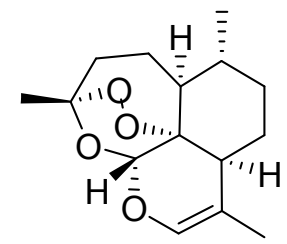

5

5 was prepared according to the references. [(a) O'Neill, P. M., et al, J. Chem. Soc., Perkin Trans. 1 2001, 2682 - 2689. (b) Sy, L.-K., et al, J. Chem. Soc., Perkin Trans. 1 2001, 2421 - 2429. (c) Haynes, R. K., et al, Eur. J. Org. Chem. 2003, 2098 - 2114. (d) Liu, Y.; Wong, V. K. W.; Ko, B. C. B.; Wong, M. K.; Che, C. M. Org. Lett. 2005, 7, 1561-1564.]

Bi-10-[(3R,5aS,6R,8aS,9R,10S,12R,12aR)-decahydro-3,6,9-trimethyl-3,12-epoxy-12Hpyrano[4,3-j]-1,2-benzodioxepin-10-ol]-maleate (6)

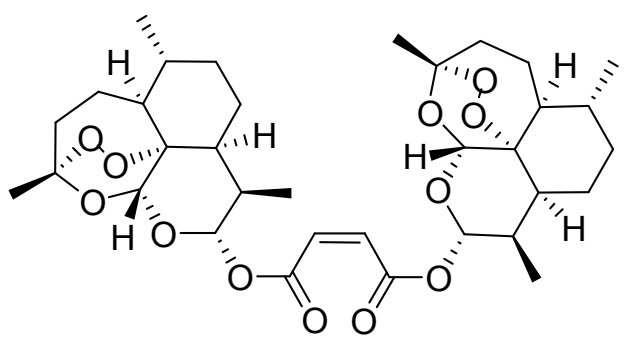

6

To a solution of $[\mathrm{Ru}(\mathrm{TTP}) \mathrm{CO}](4 \mathrm{mg}, 5 \mathrm{~mol} \%)$ in $2 \mathrm{~mL}$ of anhydrous $\mathrm{CH}_{2} \mathrm{Cl}_{2}$, diazoester 3 (35 mg, $0.1 \mathrm{mmol}$, in $3 \mathrm{~mL}$ of anhydrous $\mathrm{CH}_{2} \mathrm{Cl}_{2}$ ) was added dropwise via a syringe pump for 2 $\mathrm{h}$ under reflux. The mixture was stirred for an additional one hour. Then, the mixture was 
concentrated under reduced pressure and the residue was purified by flash column chromatography to give $6(13 \mathrm{mg}, 0.02 \mathrm{mmol}, 40 \%)$ as a colorless oil. ${ }^{1} \mathrm{H} \mathrm{NMR}\left(\mathrm{CDCl}_{3}, 400\right.$ MHz) $\delta 6.35$ (s, 2 H), 5.86 (d, J=9.9 Hz, 2 H), 5.45 (s, 2 H), 2.60 (m, 2 H), 2.37 (m, 2 H), 2.05 (m, 2 H), 1.90-1.21 (m, 16 H), 1.44 (s, $6 \mathrm{H}), 1.03-0.95$ (m, 2 H), 0.96 (d, $J=5.9 \mathrm{~Hz}, 6 \mathrm{H}), 0.89$ $(\mathrm{d}, J=7.1 \mathrm{~Hz}, 6 \mathrm{H}) ;{ }^{13} \mathrm{C} \mathrm{NMR}\left(\mathrm{CDCl}_{3}, 100 \mathrm{MHz}\right) \delta 163.70,130.29,104.51,92.75,91.57,80.13$, 51.58, 45.35, 37.34, 36.25, 34.15, 31.90, 25.98, 24.63. 22.05, 20.25, 12.10; IR $\left(\mathrm{CH}_{2} \mathrm{Cl}_{2}\right) 2916$, $1653,1559,1457,1025 \mathrm{~cm}^{-1}$; MS (FAB) $m / z 649\left([\mathrm{M}+\mathrm{H}]^{+}\right)$, HRMS (FAB) $m / z$ for $\mathrm{C}_{34} \mathrm{H}_{49} \mathrm{O}_{12}$ $\left([\mathrm{M}+\mathrm{H}]^{+}\right)$; calcd 649.3224, found 649.3222.

\section{(3R,5aS,6R,8aS,9R,12R,12aR)-decahydro-3,6,9-trimethyl-3,12-epoxy-12H-pyrano[4,3-j]-}

\section{1,2-benzodioxepin-9-ol (7)}

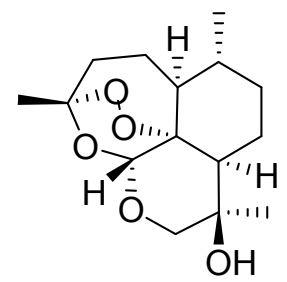

7

To a solution of $5(133 \mathrm{mg}, 0.50 \mathrm{mmol})$ in anhydrous diethyl ether $(20 \mathrm{~mL})$ was added a $\mathrm{BH}_{3} \cdot \mathrm{SMe}_{2}$ solution $\left(0.50 \mathrm{mmol}, 0.5 \mathrm{~mL}, 1 \mathrm{M}\right.$ in THF) at $-20^{\circ} \mathrm{C}$. After the disappearance of 5 in $5 \mathrm{~h}$ as indicated by TLC, saturated $\mathrm{Na}_{2} \mathrm{CO}_{3}$ solution $(1.0 \mathrm{~mL})$ was added dropwise to the reaction mixture, followed by addition of $30 \% \mathrm{H}_{2} \mathrm{O}_{2}(0.5 \mathrm{~mL})$. After stirring for $30 \mathrm{~min}$, the aqueous layer was extracted with diethyl ether $(3 \times 20 \mathrm{~mL})$, and the combined organic layer was washed with water and brine, dried over anhydrous $\mathrm{MgSO}_{4}$, filtered, and concentrated under reduced pressure. The residue was purified by flash column chromatography to give 7 (121 $\mathrm{mg}, 0.43 \mathrm{mmol}, 85 \%$ yield) as a colorless oil. ${ }^{1} \mathrm{H} \mathrm{NMR}\left(\mathrm{CDCl}_{3}, 400 \mathrm{MHz}\right) \delta 5.22(\mathrm{~s}, 1 \mathrm{H}), 3.73(\mathrm{~d}, J=11.6 \mathrm{~Hz}, 1 \mathrm{H})$, 
$3.62(\mathrm{~d}, J=11.6 \mathrm{~Hz}, 1 \mathrm{H}), 2.34(\mathrm{~m}, 1 \mathrm{H}), 2.05(\mathrm{~m}, 2 \mathrm{H}), 1.92(\mathrm{~m}, 1 \mathrm{H}), 1.71(\mathrm{~m}, 2 \mathrm{H}), 1.58(\mathrm{~s}, 3$ H), 1.51-1.19 (m, $4 \mathrm{H}), 1.42$ (s, $3 \mathrm{H}), 1.08-0.90(\mathrm{~m}, 1 \mathrm{H}), 0.96(\mathrm{~d}, J=6.2 \mathrm{~Hz}, 3 \mathrm{H}) ;{ }^{13} \mathrm{C} \mathrm{NMR}$ $\left(\mathrm{CDCl}_{3}, 100 \mathrm{MHz}\right) \delta 103.66,91.96,81.58,69.87,69.27,52.20,50.34,37.34,36.32,33.77,29.07$, 25.73, 24.43, 23.80, 20.20; MS (EI) $m / z 284\left(\mathrm{M}^{+}\right)$; HRMS (EI) $\mathrm{m} / z$ for $\mathrm{C}_{15} \mathrm{H}_{24} \mathrm{O}_{5}\left(\mathrm{M}^{+}\right.$); calcd 284.1624, found 284.1620 .

(3R,5aS,6R,8aS,9R,12R,12aR)-9-diazoacetate, decahydro-3,6,9-trimethyl-3,12-epoxy-12Hpyrano[4,3-j]-1,2-benzodioxepin-9-ol (8)

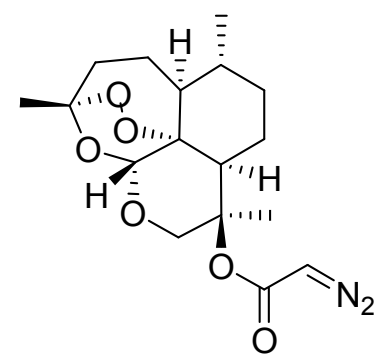

8

8 was prepared from 7 in $68 \%$ yield as a pale yellow oil according to the procedure for the preparation of 3. ${ }^{1} \mathrm{H} \mathrm{NMR}\left(\mathrm{CDCl}_{3}, 400 \mathrm{MHz}\right) \delta 5.21(\mathrm{~s}, 1 \mathrm{H}), 4.67$ (br s, $\left.1 \mathrm{H}\right), 3.72(\mathrm{~s}, 2 \mathrm{H}), 2.49$ (m, $1 \mathrm{H}), 2.35(\mathrm{~m}, 1 \mathrm{H}), 2.05(\mathrm{~m}, 1 \mathrm{H}), 1.93(\mathrm{~s}, 3 \mathrm{H}), 1.92(\mathrm{~m}, 1 \mathrm{H}), 1.70(\mathrm{~m}, 2 \mathrm{H}), 1.51-1.21(\mathrm{~m}$, $4 \mathrm{H}), 1.42$ (s, $3 \mathrm{H}), 1.14-1.03(\mathrm{~m}, 1 \mathrm{H}), 0.95(\mathrm{~d}, J=6.2 \mathrm{~Hz}, 3 \mathrm{H}) ;{ }^{13} \mathrm{C} \mathrm{NMR}\left(\mathrm{CDCl}_{3}, 100 \mathrm{MHz}\right) \delta$ $104.10,92.39,81.21,80.46,67.31,52.04,48.02,37.24,36.19,33.55,25.62,25.18,24.43,23.88$, 20.18; IR $\left(\mathrm{CH}_{2} \mathrm{Cl}_{2}\right)$ 2927, 1717, 1377, $1101 \mathrm{~cm}^{-1}$; MS (EI) $\mathrm{m} / \mathrm{z} 320\left(\left[\mathrm{M}-\mathrm{O}_{2}\right]^{+}\right)$; HRMS (EI) $\mathrm{m} / \mathrm{z}$ for $\mathrm{C}_{17} \mathrm{H}_{24} \mathrm{~N}_{2} \mathrm{O}_{4}\left(\left[\mathrm{M}-\mathrm{O}_{2}\right]^{\dagger}\right)$; calcd 320.1736, found 320.1736. 


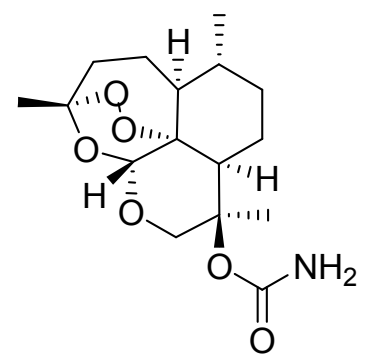

9

9 was prepared from 7 in $74 \%$ yield as a colorless oil according to the procedure for the preparation of 4. ${ }^{1} \mathrm{H} \mathrm{NMR}\left(\mathrm{CDCl}_{3}, 400 \mathrm{MHz}\right) \delta 5.21(\mathrm{~s}, 1 \mathrm{H}), 4.58(\mathrm{br} \mathrm{s}, 2 \mathrm{H}), 3.68$ (br s, $\left.2 \mathrm{H}\right)$, $2.50(\mathrm{~m}, 1 \mathrm{H}), 2.34(\mathrm{~m}, 1 \mathrm{H}), 2.05(\mathrm{~m}, 1 \mathrm{H}), 1.92(\mathrm{~m}, 1 \mathrm{H}), 1.90(\mathrm{~s}, 3 \mathrm{H}), 1.72(\mathrm{~m}, 1 \mathrm{H}), 1.58(\mathrm{~m}$, $1 \mathrm{H}), 1.51-1.19(\mathrm{~m}, 4 \mathrm{H}), 1.42(\mathrm{~s}, 3 \mathrm{H}), 1.12-1.03(\mathrm{~m}, 1 \mathrm{H}), 0.95(\mathrm{~d}, J=6.2 \mathrm{~Hz}, 3 \mathrm{H}) ;{ }^{13} \mathrm{C}$ NMR $\left(\mathrm{CDCl}_{3}, 100 \mathrm{MHz}\right) \delta 155.23,104.09,92.48,81.19,78.64,67.57,52.04,47.89,37.30,36.21$, 33.59, 25.65, 24.87, 24.47, 23.78, 20.21; IR $\left(\mathrm{CH}_{2} \mathrm{Cl}_{2}\right) 2937,1719,1353,1125 \mathrm{~cm}^{-1}$; MS (EI) $\mathrm{m} / \mathrm{z}$ $295\left(\left[\mathrm{M}-\mathrm{O}_{2}\right]^{+}\right)$; HRMS (EI) $\mathrm{m} / z$ for $\mathrm{C}_{16} \mathrm{H}_{25} \mathrm{NO}_{4}\left(\left[\mathrm{M}-\mathrm{O}_{2}\right]^{+}\right)$; calcd 295.1784, found 295.1785.

(3R,5aS,6R,8aS,9R,12R,12aR)-9-sulfamate, decahydro-3,6,9-trimethyl-3,12-epoxy-12Hpyrano[4,3-j]-1,2-benzodioxepin-9-ol (10)

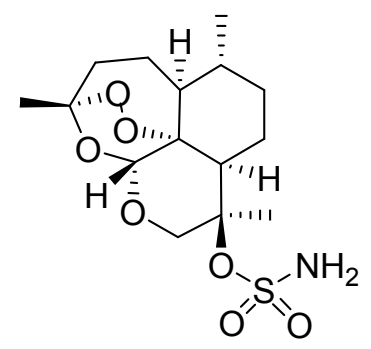

10

Formic acid $(189 \mu \mathrm{L}, 5.0 \mathrm{mmol})$ was added to neat $\mathrm{ClSO}_{2} \mathrm{NCO}(435 \mu \mathrm{L}, 5.0 \mathrm{mmol})$ at $0{ }^{\circ} \mathrm{C}$ with rapid stirring. Vigorous gas evolution was observed during the addition process, and the 
mixture solidified within 5 min. To the resulting white mass of solid was added $3.0 \mathrm{~mL}$ of $\mathrm{CH}_{2} \mathrm{Cl}_{2}$ and the mixture was then warmed to room temperature. After stirring overnight, the mixture was cooled to $-40{ }^{\circ} \mathrm{C}$ and a solution of $7(142 \mathrm{mg}, 0.50 \mathrm{mmol})$ in $2.5 \mathrm{~mL}$ of $\mathrm{CH}_{2} \mathrm{Cl}_{2}$ was dropwise added. Triethyl amine $\left(1.5 \mathrm{~g}, 15 \mathrm{mmol}\right.$, in $15 \mathrm{~mL}$ of anhydrous $\left.\mathrm{CH}_{2} \mathrm{Cl}_{2}\right)$ was used to keep the solution at $\mathrm{pH} 5.0$. The reaction was stirred at this temperature for $1 \mathrm{~h}$, then, the mixture was diluted with $150 \mathrm{~mL}$ of $\mathrm{Et}_{2} \mathrm{O}$ and washed with saturated $\mathrm{NaHCO}_{3}$, water, brine, dried over $\mathrm{MgSO}_{4}$, and concentrated under reduced pressure to give a mixture of sulfamate $\mathbf{1 0}$ and alcohol $\mathbf{7}$ $\left(\mathbf{1 0 : 7}=1: 4\right.$ by ${ }^{1} \mathrm{H}$ NMR). Sulfamate $\mathbf{1 0}$ easily decomposed to $\mathbf{5}$ and could not be purified by flash column chromatography. Thus, the mixture was used in the subsequent $\mathrm{C}-\mathrm{H}$ insertion reaction without further purification.

(3R,5aS,6R,8aS,9R,12R,12aR)-9,9-[dihydrofuran-3'(4'H)-one]-decahydro-3,6-dimethyl-

3,12-epoxy-12H-pyrano[4,3-j]-1,2-benzodioxepin (11)

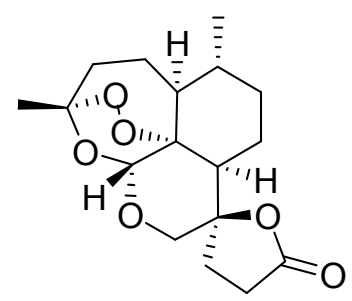

11

To a solution of $\mathrm{Rh}_{2}(\mathrm{OAc})_{4}(2 \mathrm{mg}, 5 \mathrm{~mol} \%)$ in $2 \mathrm{~mL}$ of anhydrous $\mathrm{CH}_{2} \mathrm{Cl}_{2}$, diazoester 8 (35 $\mathrm{mg}, 0.1 \mathrm{mmol}$, in $3 \mathrm{~mL}$ of anhydrous $\mathrm{CH}_{2} \mathrm{Cl}_{2}$ ) was added dropwise via a syringe pump for $2 \mathrm{~h}$ under reflux. The mixture was stirred for an additional one hour. Then, the mixture was concentrated under reduced pressure and the residue was purified by flash column chromatography to give 11 (29 mg, $0.089 \mathrm{mmol}, 89 \%)$ as a colorless oil. ${ }^{1} \mathrm{H} \mathrm{NMR}\left(\mathrm{CDCl}_{3}, 400\right.$ MHz) $\delta 5.27$ (s, $1 \mathrm{H}), 3.81(\mathrm{~d}, J=11.8 \mathrm{~Hz}, 1 \mathrm{H}), 3.68(\mathrm{~d}, J=11.8 \mathrm{~Hz}, 1 \mathrm{H}), 2.93(\mathrm{~m}, 1 \mathrm{H}), 2.68-$ 
2.53 (m, 2 H), 2.39-2.29 (m, 2 H), 2.06 (m, 2 H), $1.92(\mathrm{~m}, 2 \mathrm{H}), 1.72(\mathrm{~m}, 1 \mathrm{H}), 1.51-1.21(\mathrm{~m}, 4$ H), $1.42(\mathrm{~s}, 3 \mathrm{H}), 1.12-1.00(\mathrm{~m}, 1 \mathrm{H}), 0.97(\mathrm{~d}, J=6.2 \mathrm{~Hz}, 3 \mathrm{H}) ;{ }^{13} \mathrm{C} \mathrm{NMR}\left(\mathrm{CDCl}_{3}, 100 \mathrm{MHz}\right) \delta$ $176.11,104.34,92.18,82.79,81.77,64.46,52.08,50.01,37.27,36.16,33.37,33.02,27.87,25.67$, 24.33, 23.84, 20.11; IR $\left(\mathrm{CH}_{2} \mathrm{Cl}_{2}\right) 2928,1780,1559,1101 \mathrm{~cm}^{-1}$; MS (EI) $\mathrm{m} / z 292\left(\left[\mathrm{M}-\mathrm{O}_{2}\right]^{+}\right)$; HRMS (EI) $m / z$ for $\mathrm{C}_{17} \mathrm{H}_{24} \mathrm{O}_{4}\left(\left[\mathrm{M}-\mathrm{O}_{2}\right]^{+}\right)$, calcd 292.1675, found 292.1674 .

\section{Bi-9-[(3R,5aS,6R,8aS,9R,12R,12aR)-decahydro-3,6,9-trimethyl-3,12-epoxy-12H-} pyrano[4,3-j]-1,2-benzodioxepin-9-ol]-maleate (12)

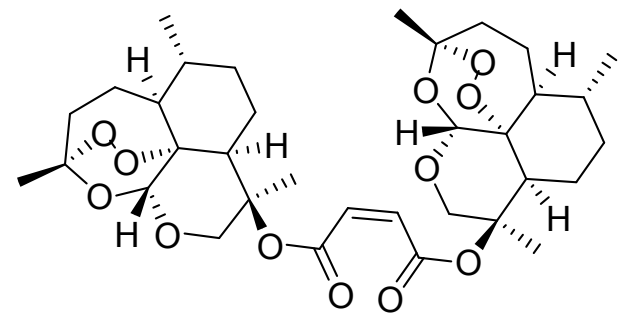

12

To a solution of $\left[\mathrm{Ru}(\mathrm{TTP}) \mathrm{CO}\right.$ ] (4 mg, $5 \mathrm{~mol} \%$ ) in $2 \mathrm{~mL}$ of anhydrous $\mathrm{CH}_{2} \mathrm{Cl}_{2}$, diazoester 8 (35 mg, $0.1 \mathrm{mmol}$, in $3 \mathrm{~mL}$ of anhydrous $\mathrm{CH}_{2} \mathrm{Cl}_{2}$ ) was added dropwise via a syringe pump for 2 $\mathrm{h}$ under reflux. The mixture was stirred for an additional one hour. Then, the mixture was concentrated under reduced pressure and the residue was purified by flash column chromatography to give $12(12 \mathrm{mg}, 0.018 \mathrm{mmol}, 37 \%) .{ }^{1} \mathrm{H}$ NMR $\left(\mathrm{CDCl}_{3}, 400 \mathrm{MHz}\right) \delta 6.08(\mathrm{~s}, 2$ H), $5.21(\mathrm{~s}, 2 \mathrm{H}), 3.76(\mathrm{~s}, 4 \mathrm{H}), 2.49(\mathrm{~m}, 2 \mathrm{H}), 2.35(\mathrm{~m}, 2 \mathrm{H}), 2.05(\mathrm{~m}, 2 \mathrm{H}), 1.94(\mathrm{~s}, 6 \mathrm{H}), 1.92(\mathrm{~m}$, $2 \mathrm{H}), 1.70(\mathrm{~m}, 4 \mathrm{H}), 1.51-1.21(\mathrm{~m}, 8 \mathrm{H}), 1.42(\mathrm{~s}, 6 \mathrm{H}), 1.14-1.03(\mathrm{~m}, 2 \mathrm{H}), 0.95(\mathrm{~d}, J=6.2 \mathrm{~Hz}, 6$ $\mathrm{H}) ;{ }^{13} \mathrm{C} \mathrm{NMR}\left(\mathrm{CDCl}_{3}, 100 \mathrm{MHz}\right) \delta 174.84,129.99,118.20,92.37,81.39,81.29,67.20,52.09$, 47.75, 37.30, 36.24, 33.59, 25.66, 24.60, 24.48, 23.86, 20.19; IR $\left(\mathrm{CH}_{2} \mathrm{Cl}_{2}\right) 2920,1732,1559$, $1102 \mathrm{~cm}^{-1}$; MS (FAB) $m / z 649\left([\mathrm{M}+\mathrm{H}]^{+}\right)$, HRMS (FAB) $m / z$ for $\mathrm{C}_{34} \mathrm{H}_{49} \mathrm{O}_{12}\left([\mathrm{M}+\mathrm{H}]^{+}\right)$; calcd 649.3224 , found 649.3223 
(3R,5aS,6R,8aS,9R,10S,12R,12aR)-decahydro-3,6,9-trimethyl-3,12-epoxy-12H-[pyrano[2,3d]oxazol-2-one]-pyrano[4,3-j]-1,2-benzodioxepin-10-amino-9-ol (13)

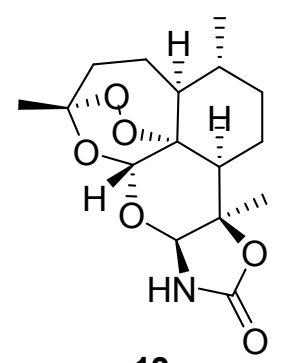

13

To a mixture of carbamate $9(33 \mathrm{mg}, 0.1 \mathrm{mmol}), \mathrm{PhI}(\mathrm{OAc})_{2}(0.2 \mathrm{mmol})$, and $\mathrm{MgO}(0.2 \mathrm{mmol})$ in $5 \mathrm{~mL}$ of anhydrous $\mathrm{CH}_{2} \mathrm{Cl}_{2}, \mathrm{Rh}_{2}(\mathrm{OAc})_{4}(2 \mathrm{mg}, 5 \mathrm{~mol} \%)$ was added and the reaction was stirred for $24 \mathrm{~h}$ under reflux. Then, the mixture was concentrated under reduced pressure and the residue was purified by flash column chromatography to give $\mathbf{1 3}$ ( $7 \mathrm{mg}, 85 \%$ yield based on $27 \%$ conversion, $23 \mathrm{mg}$ of 9 recovered) as a colorless oil. ${ }^{1} \mathrm{H} \mathrm{NMR}\left(\mathrm{CDCl}_{3}, 400 \mathrm{MHz}\right) \delta 5.53$ (br s, 1 H), $5.45(\mathrm{~s}, 1 \mathrm{H}), 5.40(\mathrm{~s}, 1 \mathrm{H}), 2.50(\mathrm{~m}, 1 \mathrm{H}), 2.31(\mathrm{~m}, 1 \mathrm{H}), 2.08-1.98(\mathrm{~m}, 3 \mathrm{H}), 1.92(\mathrm{~m}, 1 \mathrm{H})$, $1.55(\mathrm{~s}, 3 \mathrm{H}), 1.42(\mathrm{~s}, 3 \mathrm{H}), 1.42-1.24(\mathrm{~m}, 4 \mathrm{H}), 1.02(\mathrm{~m}, 1 \mathrm{H}), 0.99(\mathrm{~d}, J=5.8 \mathrm{~Hz}, 3 \mathrm{H}) ;{ }^{13} \mathrm{C}$ NMR $\left(\mathrm{CDCl}_{3}, 100 \mathrm{MHz}\right) \delta 158.24,103.07,88.91,83.75,83.04,80.89,50.80,48.95,37.46$, $36.35,33.56,27.19,25.48,24.72,24.41,19.66$; IR $\left(\mathrm{CH}_{2} \mathrm{Cl}_{2}\right) 2920,1770,1100,1010 \mathrm{~cm}^{-1}$; MS (FAB) $m / z 326\left([\mathrm{M}+\mathrm{H}]^{+}\right)$; HRMS (FAB) $m / z$ for $\mathrm{C}_{16} \mathrm{H}_{24} \mathrm{O}_{6} \mathrm{~N}\left([\mathrm{M}+\mathrm{H}]^{+}\right)$; calcd 326.1604, found 326.1597 . 
(3R,5aS,6R,8S,8aS,9R,12R,12aR)-[10,9,8-cd]-sulfamidate, decahydro-3,6,9-trimethyl-3,12epoxy-12H-pyrano[4,3-j]-1,2-benzodioxepin-8-amino-9-ol (14)

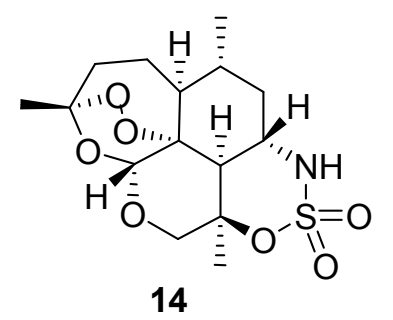

To a mixture of sulfamate $\mathbf{1 0}$ and alcohol $\mathbf{7}(\mathbf{1 0}+\mathbf{7}=0.5 \mathrm{mmol}, \mathbf{1 0 : 7}=1: 4)$ in $5 \mathrm{~mL}$ of anhydrous $\mathrm{CH}_{2} \mathrm{Cl}_{2}, \mathrm{PhI}(\mathrm{OAc})_{2}(0.2 \mathrm{mmol}), \mathrm{MgO}(0.2 \mathrm{mmol})$, and $\mathrm{Rh}_{2}(\mathrm{OAc})_{4}(2 \mathrm{mg}, 5 \mathrm{~mol} \%)$ was added and the reaction was stirred for $3 \mathrm{~h}$ under reflux. Then, the mixture was concentrated under reduced pressure and the residue was purified by flash column chromatography to give $\mathbf{1 4}$ (30 mg, 85\%, $113 \mathrm{mg}$ of 7 recovered) as a colorless oil. ${ }^{1} \mathrm{H} \mathrm{NMR}\left(\mathrm{CDCl}_{3}, 400 \mathrm{MHz}\right) \delta 6.38(\mathrm{~d}, J$ $=11 \mathrm{~Hz}, 1 \mathrm{H}), 5.38(\mathrm{~s}, 1 \mathrm{H}), 4.28(\mathrm{~d}, J=12.2 \mathrm{~Hz}, 1 \mathrm{H}), 3.84(\mathrm{~d}, J=12.2 \mathrm{~Hz}, 1 \mathrm{H}), 3.80(\mathrm{~m}, 1 \mathrm{H})$, $2.28(\mathrm{~m}, 1 \mathrm{H}), 2.05(\mathrm{~m}, 1 \mathrm{H}), 1.98-1.86(\mathrm{~m}, 3 \mathrm{H}), 1.66(\mathrm{~m}, 1 \mathrm{H}), 1.66(\mathrm{~s}, 3 \mathrm{H}), 1.49-1.24(\mathrm{~m}, 3 \mathrm{H})$, $1.32(\mathrm{~s}, 3 \mathrm{H}), 1.02(\mathrm{~d}, J=6.4 \mathrm{~Hz}, 3 \mathrm{H}) ;{ }^{13} \mathrm{C} \mathrm{NMR}\left(\mathrm{CDCl}_{3}, 100 \mathrm{MHz}\right) \delta 104.50,92.13,88.87$, $82.09,67.47,52.87,52.67,51.86,39.95,36.80,34.68,27.76,25.78,24.76,20.00 ; \mathrm{IR}\left(\mathrm{CH}_{2} \mathrm{Cl}_{2}\right)$ 2920, 1351, 1159, $1023 \mathrm{~cm}^{-1}$; MS (EI) m/z $329\left(\left[\mathrm{M}-\mathrm{O}_{2}\right]^{+}\right)$; HRMS (EI) $m / z$ for $\mathrm{C}_{15} \mathrm{H}_{23} \mathrm{NO}_{5} \mathrm{~S}([\mathrm{M}-$ $\left.\mathrm{O}_{2}\right]^{+}$); calcd 329.1297, found 329.1302. 
(3aS,4R,6aS,7R,10S,10aR)-10-(acetyloxy)octahydro-4,7-dimethyl-8H,10H-furo[3,2-

i][2]benzopyran-8-one (15) and (3R,3aS,6R,6aS,8R,9S,10aS,10bR)-octahydro-8-hydroxy3,6,9-trimethyl-10aH-9,10b-epoxypyrano[4,3,2-jk][2]benzoxepin-2(3H)-one (16)

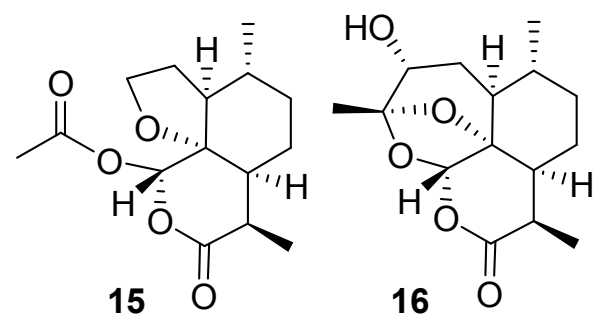

To a solution of artemisinin $(1,28 \mathrm{mg}, 0.1 \mathrm{mmol})$ and $\mathrm{Rh}_{2}(\mathrm{OAc})_{4}(2 \mathrm{mg}, 5 \mathrm{~mol} \%)$ in $2 \mathrm{~mL}$ of anhydrous $\mathrm{CH}_{2} \mathrm{Cl}_{2}$, ethyl diazoacetate (EDA, $22 \mathrm{mg}, 0.2 \mathrm{mmol}$, in $3 \mathrm{~mL}$ of anhydrous $\mathrm{CH}_{2} \mathrm{Cl}_{2}$ ) was added dropwise via a syringe pump for $2 \mathrm{~h}$ under reflux. The mixture was stirred for an additional one hour. Then, the mixture was concentrated under reduced pressure and the residue was purified by flash column chromatography to give 15 ( $1 \mathrm{mg}, 5 \%$ yield) and $\mathbf{1 6}(1 \mathrm{mg}, 5 \%$ yield) and $25 \mathrm{mg}$ of $\mathbf{1}$ was recovered. The characterization data of $\mathbf{1 5}$ and $\mathbf{1 6}$ matched those reported in literature [Lin, A. J.; Klayman, D. L.; Hoch, J. M.; Silverton, J. V.; George, C. F. J. Org. Chem. 1985, 50, 4504-4508.]. 
(3R,5aS,6R,8aS,9R,12R,12aR)-decahydro-3,6-dimethyl-9-(3'-hydroxypropanyl)-3,12epoxy-12H-pyrano[4,3-j]-1,2-benzodioxepin-9-ol (17)

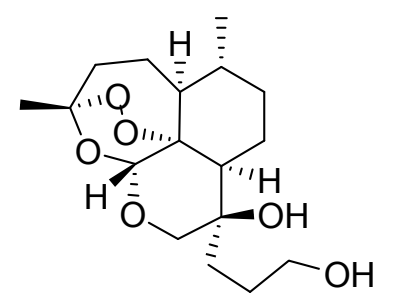

17

To a solution of $11(32 \mathrm{mg}, 0.10 \mathrm{mmol})$ in anhydrous diethyl ether $(10 \mathrm{~mL})$ was added $\mathrm{LiAlH}_{4}(4 \mathrm{mg}, 0.10 \mathrm{mmol})$ at $0{ }^{\circ} \mathrm{C}$, after the disappearance of $\mathbf{1 1}$ in $1 \mathrm{~h}$ as indicated by TLC, 30 $\mathrm{mL}$ of ethyl acetate was added to the reaction mixture, followed by addition of $\mathrm{Na}_{2} \mathrm{SO}_{4} \cdot 10 \mathrm{H}_{2} \mathrm{O}(1$ g). After stirring for $30 \mathrm{~min}$, the precipitate was filtered off and the filtrate was concentrated under reduced pressure. The residue was purified by flash column chromatography to give 17 (31 mg, $0.93 \mathrm{mmol}, 93 \%$ yield) as a colorless oil. ${ }^{1} \mathrm{H} \mathrm{NMR}\left(\mathrm{CDCl}_{3}, 400 \mathrm{MHz}\right) \delta 5.24(\mathrm{~s}, 1 \mathrm{H})$, $3.75(\mathrm{~m}, 2 \mathrm{H}), 3.65$ (m, $2 \mathrm{H}), 2.38-2.28(\mathrm{~m}, 2 \mathrm{H}), 2.03(\mathrm{~m}, 2 \mathrm{H}), 1.92-1.68(\mathrm{~m}, 7 \mathrm{H}), 1.50-1.21(\mathrm{~m}$, $3 \mathrm{H}), 1.41(\mathrm{~s}, 3 \mathrm{H}), 1.12-1.00(\mathrm{~m}, 1 \mathrm{H}), 0.96(\mathrm{~d}, J=6.2 \mathrm{~Hz}, 3 \mathrm{H}) ;{ }^{13} \mathrm{C} \mathrm{NMR}\left(\mathrm{CDCl}_{3}, 100 \mathrm{MHz}\right) \delta$ $103.62,92.05,81.78,70.25,69.67,63.41,52.29,46.93,37.37,37.18,36.36,33.95,25.98,25.75$, 24.48, 23.97, 20.21; IR $\left(\mathrm{CH}_{2} \mathrm{Cl}_{2}\right) 2925,1653,1559,1457,1069 \mathrm{~cm}^{-1}$; MS (FAB) $\mathrm{m} / z 327$ ([M$\left.\mathrm{H}]^{+}\right)$; HRMS (FAB) $m / z$ for $\mathrm{C}_{17} \mathrm{H}_{27} \mathrm{O}_{6}\left([\mathrm{M}-\mathrm{H}]^{+}\right)$, calcd 327.1808, found 327.1806 . 
(3R,5aS,6R,8aS,9R,10S,12R,12aR)-(3'-tert-butylcarbamate)-decahydro-3,6,9-trimethyl-

3,12-epoxy-12H-[pyrano[2,3-d]oxazol-2-one]-pyrano[4,3-j]-1,2-benzodioxepin-10-amino-9-

ol (18)

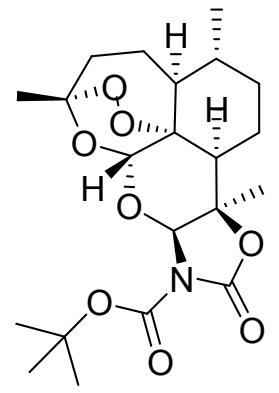

18

To a solution of 13 (32 mg, $0.1 \mathrm{mmol})$, DMAP (5 mg), and $\mathrm{Et}_{3} \mathrm{~N}(20 \mathrm{mg}, 0.2 \mathrm{mmol})$ in $5 \mathrm{~mL}$ of anhydrous $\mathrm{CH}_{2} \mathrm{Cl}_{2}$, (Boc) $)_{2} \mathrm{O}(26 \mathrm{mg}, 0.15 \mathrm{mmol})$ was added and the reaction mixture was stirred for $2 \mathrm{~h}$ at room temperature. Then, the mixture was diluted with $30 \mathrm{~mL}$ of $\mathrm{CH}_{2} \mathrm{Cl}_{2}$ and washed with saturated $\mathrm{NH}_{4} \mathrm{Cl}$, water, brine, dried over $\mathrm{MgSO}_{4}$, and concentrated under reduced pressure, and the residue was purified by flash column chromatography to give $\mathbf{1 8}$ (39 $\mathrm{mg}, 0.91$ mmol, 91\% yield) as a colorless oil. ${ }^{1} \mathrm{H} \mathrm{NMR}\left(\mathrm{CDCl}_{3}, 300 \mathrm{MHz}\right) \delta 5.81(\mathrm{~s}, 1 \mathrm{H}), 5.45(\mathrm{~s}, 1 \mathrm{H})$, $2.32(\mathrm{~m}, 1 \mathrm{H}), 2.10-1.88(\mathrm{~m}, 4 \mathrm{H}), 1.73(\mathrm{~m}, 1 \mathrm{H}), 1.65-1.24(\mathrm{~m}, 4 \mathrm{H}), 1.57(\mathrm{~s}, 9 \mathrm{H}), 1.53(\mathrm{~s}, 3 \mathrm{H})$, $1.42(\mathrm{~s}, 3 \mathrm{H}), 1.02(\mathrm{~m}, 1 \mathrm{H}), 0.99(\mathrm{~d}, J=5.2 \mathrm{~Hz}, 3 \mathrm{H}) ;{ }^{13} \mathrm{C} \mathrm{NMR}\left(\mathrm{CDCl}_{3}, 75 \mathrm{MHz}\right) \delta 151.45$, $148.47,102.93,89.00,84.08,80.71,50.65,48.82,37.40,36.27,33.48,27.98,27.28,25.41,24.74$, 24.38, 19.65; IR $\left(\mathrm{CH}_{2} \mathrm{Cl}_{2}\right)$ 2958, 1824, 1372, 1156, $1077 \mathrm{~cm}^{-1}$; MS (FAB) $\mathrm{m} / z 426\left([\mathrm{M}+\mathrm{H}]^{+}\right)$; HRMS (FAB) $m / z$ for $\mathrm{C}_{21} \mathrm{H}_{31} \mathrm{NO}_{8}\left([\mathrm{M}+\mathrm{H}]^{+}\right)$, calcd 426.2128, found 426.2125. 
(3R,5aS,6R,8aS,9R,10S,12R,12aR)-10-tert-butylcarbamate, decahydro-3,6,9-trimethyl-

3,12-epoxy-12H-pyrano[4,3-j]-1,2-benzodioxepin-10-amino-9-ol (19)

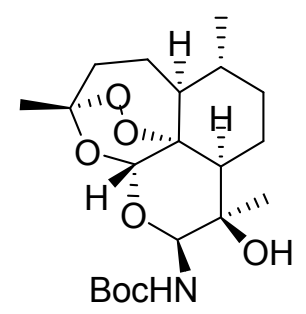

19

$42 \mathrm{mg}$ of $18(0.1 \mathrm{mmol})$ was added to a mixture of $5 \mathrm{~mL}$ of $1 \mathrm{~N} \mathrm{NaOH}$ and $10 \mathrm{~mL}$ of $\mathrm{THF}$ and the reaction mixture was stirred for $3 \mathrm{~h}$ under reflux. Then, the mixture was diluted with 30 $\mathrm{mL}$ of $\mathrm{CH}_{2} \mathrm{Cl}_{2}$. After separating the aqueous layer, the organic layer was washed with saturated $\mathrm{NH}_{4} \mathrm{Cl}$, water, brine, dried over $\mathrm{MgSO}_{4}$, and concentrated under reduced pressure, the residue was purified by flash column chromatography to give 19 (colorless oil, $26 \mathrm{mg}, 0.065 \mathrm{mmol}, 65 \%$ yield) and 13 (10 mg, $0.03 \mathrm{mmol}, 30 \%$ yield). ${ }^{1} \mathrm{H}$ NMR $\left(\mathrm{CDCl}_{3}, 500 \mathrm{MHz}\right) \delta 5.92(\mathrm{~d}, J=8.8 \mathrm{~Hz}$, $1 \mathrm{H}), 5.74(\mathrm{~d}, J=8.8 \mathrm{~Hz}, 1 \mathrm{H}), 5.37(\mathrm{~s}, 1 \mathrm{H}), 2.31(\mathrm{~m}, 1 \mathrm{H}), 2.08(\mathrm{~m}, 1 \mathrm{H}), 1.97-1.88(\mathrm{~m}, 2 \mathrm{H})$, $1.80(\mathrm{~m}, 1 \mathrm{H}), 1.70(\mathrm{~m}, 1 \mathrm{H}), 1.48(\mathrm{~s}, 3 \mathrm{H}), 1.46(\mathrm{~s}, 9 \mathrm{H}), 1.43-1.15(\mathrm{~m}, 4 \mathrm{H}), 1.31(\mathrm{~s}, 3 \mathrm{H}), 1.02$ $(\mathrm{m}, 1 \mathrm{H}), 0.98(\mathrm{~d}, J=5.8 \mathrm{~Hz}, 3 \mathrm{H}) ;{ }^{13} \mathrm{C} \mathrm{NMR}\left(\mathrm{CDCl}_{3}, 75 \mathrm{MHz}\right) \delta 154.86,102.42,90.16,79.25$, $72.54,51.66,51.10,37.21,36.41,33.69,28.42,28.00,25.79,24.89,24.48,19.81 ; \mathrm{IR}\left(\mathrm{CH}_{2} \mathrm{Cl}_{2}\right)$ 2926, 1717, 1507, $1010 \mathrm{~cm}^{-1}$; MS (FAB) $\mathrm{m} / z 400\left([\mathrm{M}+\mathrm{H}]^{+}\right)$; HRMS (FAB) $\mathrm{m} / z$ for $\mathrm{C}_{21} \mathrm{H}_{31} \mathrm{NO}_{8}$ $\left([\mathrm{M}+\mathrm{H}]^{+}\right)$, calcd 400.2335, found 400.2333. 
(3R,5aS,6R,8S,8aS,9R,12R,12aR)-(5'-tert-butylcarbamate)-[10,9,8-cd]-sulfamidate, decahydro-3,6,9-trimethyl-3,12-epoxy-12H-pyrano[4,3-j]-1,2-benzodioxepin-8-amino-9-ol (20)

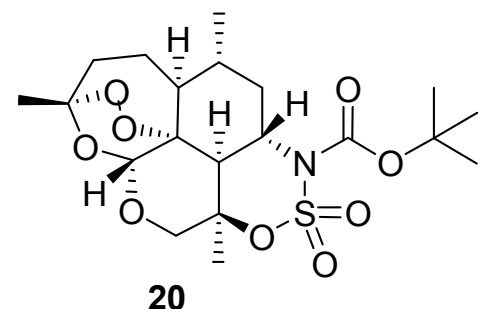

To a solution of 14 (36 mg, $0.1 \mathrm{mmol}), \mathrm{DMAP}(5 \mathrm{mg})$, and $\mathrm{Et}_{3} \mathrm{~N}(20 \mathrm{mg}, 0.2 \mathrm{mmol})$ in $5 \mathrm{~mL}$ of anhydrous $\mathrm{CH}_{2} \mathrm{Cl}_{2}$, (Boc) $)_{2} \mathrm{O}(26 \mathrm{mg}, 0.15 \mathrm{mmol})$ was added and the reaction mixture was stirred for $2 \mathrm{~h}$ at room temperature. Then, the mixture was diluted with $30 \mathrm{~mL}$ of $\mathrm{CH}_{2} \mathrm{Cl}_{2}$ and washed with saturated $\mathrm{NH}_{4} \mathrm{Cl}$, water, brine, dried over $\mathrm{MgSO}_{4}$, and concentrated under reduced pressure, and the residue was purified by flash column chromatography to give $\mathbf{2 0}$ (42 $\mathrm{mg}, 0.92$ mmol, 92\% yield) as a colorless oil. ${ }^{1} \mathrm{H}$ NMR $\left(\mathrm{CDCl}_{3}, 300 \mathrm{MHz}\right) \delta 5.35(\mathrm{~s}, 1 \mathrm{H}), 4.15(\mathrm{~d}, J=$ $12.6 \mathrm{~Hz}, 1 \mathrm{H}), 3.94$ (d, $J=12.6 \mathrm{~Hz}, 1 \mathrm{H}), 3.90(\mathrm{~m}, 1 \mathrm{H}), 2.60(\mathrm{~d}, J=12.2 \mathrm{~Hz}, 1 \mathrm{H}), 2.33(\mathrm{~m}, 1 \mathrm{H})$, 2.12-2.03 (m, $2 \mathrm{H}), 1.93(\mathrm{~m}, 1 \mathrm{H}), 1.77(\mathrm{~s}, 3 \mathrm{H}), 1.76-1.18(\mathrm{~m}, 4 \mathrm{H}), 1.52(\mathrm{~s}, 9 \mathrm{H}), 1.42(\mathrm{~s}, 3 \mathrm{H})$, $1.03(\mathrm{~d}, J=5.3 \mathrm{~Hz}, 3 \mathrm{H}) ;{ }^{13} \mathrm{C} \mathrm{NMR}\left(\mathrm{CDCl}_{3}, 75 \mathrm{MHz}\right) \delta 149.93,103.61,90.65,89.55,85.16$, $80.14,68.08,55.83,51.28,48.89,36.92,35.94,34.08,27.75,25.93,25.49,23.79,19.48$; IR $\left(\mathrm{CH}_{2} \mathrm{Cl}_{2}\right)$ 2931, 1734, 1373, $1147 \mathrm{~cm}^{-1} ; \mathrm{MS}(\mathrm{EI}) \mathrm{m} / \mathrm{z} 429\left(\left[\mathrm{M}-\mathrm{O}_{2}\right]^{+}\right) ; \mathrm{HRMS}(\mathrm{EI}) \mathrm{m} / \mathrm{z}$ for $\mathrm{C}_{20} \mathrm{H}_{31} \mathrm{NO}_{7} \mathrm{~S}\left(\left[\mathrm{M}-\mathrm{O}_{2}\right]^{+}\right)$, calcd 429.1821, found 429.1830 . 
(3R,5aS,6R,8S,8aS,12R,12aR)-3,4,5,5a,6,7,8,8a-octahydro-3,6,9-trimethyl-8-tert-

butylcarbamate-3,12-epoxy-12H-pyrano[4,3-j]-1,2-benzodioxepin (21) and

(3R,5aS,6R,8aS,12R,12aR)-decahydro-3,6-dimethyl-9-methylene-8-tert-butylcarbamate-

3,12-epoxy-12H-pyrano[4,3-j]-1,2-benzodioxepin (22)

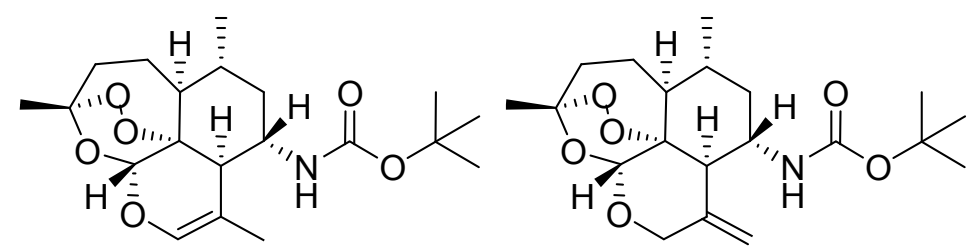

21

22

To a solution of 20 ( $23 \mathrm{mg}, 0.05 \mathrm{mmol})$ in $5 \mathrm{~mL}$ of anhydrous DMF, NaOAc (16 mg, $0.10 \mathrm{mmol})$ was added and the reaction mixture was stirred for $12 \mathrm{~h}$ at $70{ }^{\circ} \mathrm{C}$. Then, the mixture was diluted with $30 \mathrm{~mL}$ of $\mathrm{CH}_{2} \mathrm{Cl}_{2}$ and washed with water, brine, dried over $\mathrm{MgSO}_{4}$, and concentrated under reduced pressure, the residue was purified by flash column chromatography to give $\mathbf{2 1}$ (colorless oil, $6 \mathrm{mg}, 0.015 \mathrm{mmol}, 30 \%$ yield) and 22 (colorless oil, $11 \mathrm{mg}, 0.030 \mathrm{mmol}, 60 \%$ yield).

21, ${ }^{1} \mathrm{H}$ NMR (CDCl $\left.3,300 \mathrm{MHz}\right) \delta 6.32(\mathrm{~s}, 1 \mathrm{H}), 5.52(\mathrm{~s}, 1 \mathrm{H}), 4.37$ (m, $\left.1 \mathrm{H}\right), 3.56(\mathrm{~m}, 1 \mathrm{H}), 2.42$ (m, $1 \mathrm{H}), 2.03$ (m, $1 \mathrm{H}), 1.98-1.88(\mathrm{~m}, 2 \mathrm{H}), 1.69(\mathrm{~s}, 3 \mathrm{H}), 1.66(\mathrm{~m}, 1 \mathrm{H}), 1.55-1.39(\mathrm{~m}, 3 \mathrm{H})$, $1.42(\mathrm{~s}, 9 \mathrm{H}), 1.41(\mathrm{~s}, 3 \mathrm{H}), 1.15-1.08(\mathrm{~m}, 1 \mathrm{H}), 0.98(\mathrm{~d}, J=6.1 \mathrm{~Hz}, 3 \mathrm{H}) ;{ }^{13} \mathrm{C} \mathrm{NMR}\left(\mathrm{CDCl}_{3}, 125\right.$ MHz) $\delta 154.88,137.36,104.74,89.77,79.01,53.16,50.57,49.91,42.39,36.03,34.81,28.42$, 25.74, 24.16, 19.85, 19.30; IR $\left(\mathrm{CH}_{2} \mathrm{Cl}_{2}\right) 2923,1716,1456,1170,1072 \mathrm{~cm}^{-1} ; \mathrm{MS}(\mathrm{EI}) \mathrm{m} / \mathrm{z} 381$ $\left(\mathrm{M}^{+}\right)$; HRMS (EI) $m / z$ for $\mathrm{C}_{20} \mathrm{H}_{31} \mathrm{NO}_{6}\left(\mathrm{M}^{+}\right)$; calcd 381.2151, found 381.2157.

22, ${ }^{1} \mathrm{H}$ NMR $\left(\mathrm{CDCl}_{3}, 300 \mathrm{MHz}\right) \delta 5.29(\mathrm{~s}, 1 \mathrm{H}), 5.14(\mathrm{~s}, 1 \mathrm{H}), 4.93(\mathrm{~m}, 1 \mathrm{H}), 4.40(\mathrm{~d}, J=12.4 \mathrm{~Hz}$, $1 \mathrm{H}), 4.28(\mathrm{~d}, J=12.4 \mathrm{~Hz}, 1 \mathrm{H}), 4.24(\mathrm{~m}, 1 \mathrm{H}), 3.88(\mathrm{~m}, 1 \mathrm{H}), 2.38(\mathrm{~m}, 1 \mathrm{H}), 2.10-1.98(\mathrm{~m}, 2 \mathrm{H})$, 1.93-1.85 (m, 2 H), 1.55-1.25 (m, 3 H), $1.43(\mathrm{~s}, 3 \mathrm{H}), 1.38$ (s, $9 \mathrm{H}), 1.10-0.98(\mathrm{~m}, 1 \mathrm{H}), 1.01$ (d, $J$ $=6.3 \mathrm{~Hz}, 3 \mathrm{H}) ;{ }^{13} \mathrm{C} \mathrm{NMR}\left(\mathrm{CDCl}_{3}, 125 \mathrm{MHz}\right) \delta 155.25,138.42,116.09,104.33,92.36,81.57$, 66.30, 56.07, 51.54, 41.22, 36.06, 34.60, 28.29, 26.05, 24.18, 19.98; IR $\left(\mathrm{CH}_{2} \mathrm{Cl}_{2}\right) 2920,1714$, 
1457, 1168, $1062 \mathrm{~cm}^{-1}$; MS (EI) m/z $349\left(\left[\mathrm{M}-\mathrm{O}_{2}\right]^{+}\right)$; HRMS (EI) $\mathrm{m} / z$ for $\mathrm{C}_{20} \mathrm{H}_{31} \mathrm{NO}_{4}\left(\left[\mathrm{M}-\mathrm{O}_{2}\right]^{+}\right)$; calcd 349.2253, found 349.2256.

\section{(II) Cytotoxicity Studies (MTT Assay)}

Human hepatocellular carcinoma (HepG2) was maintained in a minimum essential medium with Earle's balanced salts (MEM). All the media were supplemented with $2 \mathrm{mM} L$-glutamine and $10 \%$ fetal boviene serum. Penicillin $(100 \mathrm{U} / \mathrm{mL})$ and Streptomycin $(100 \mu \mathrm{g} / \mathrm{mL})$ were added to all media. Cultures were incubated at $37{ }^{\circ} \mathrm{C}$ in a $5 \% \mathrm{CO}_{2} / 95 \%$ air humidified atmosphere.

Assays on the cytotoxic effects were conducted in 96-well flat-bottomed microtitre plates. The supplemented culture medium $(100 \mu \mathrm{L})$ with cells $\left(4 \times 10^{4}\right.$ cells $\left./ \mathrm{mL}\right)$ was added into each well and was incubated $\left(37{ }^{\circ} \mathrm{C}, 5 \% \mathrm{CO}_{2} / 95 \%\right.$ air) for $24 \mathrm{~h}$. All the media were then removed and fresh supplemented medium $(100 \mu \mathrm{L})$ was added into each well. Compounds dissolved in the culture medium $(100 \mu \mathrm{L}+<1 \%$ ethanol) were added into a set of wells. After mixing, the sample-containing media $(100 \mu \mathrm{L})$ were drawn and added to another set of wells. Such processes were repeated to provide a set of two-fold dilution series. Controlled wells only contained 100 $\mu \mathrm{L}$ of supplemented media. Microtitre plates were incubated at $37{ }^{\circ} \mathrm{C}$ in a $5 \% \mathrm{CO}_{2} / 95 \%$ air humidified atmosphere for further 6 days. All the cytotoxicity assays were run in parallel with a negative control (i.e., untreated population). Assessment of the cytotoxicity was carried out using a modified method of Mosmann based 3-(4, 5-Dimethylthiazol-2-yl)-2, 5-diphenyltetrazolium bromide (MTT) Assay [Mosmann, T. J. Immunol. Methods 1983, 65, 55 - 63.]. At the end of each incubation period, $10 \mu \mathrm{L}$ of the MTT solution (Cell Proliferation Kit I, Roche) were added into each well and the cultures were further incubated for $4 \mathrm{~h}$ at $37{ }^{\circ} \mathrm{C}$ in a $5 \% \mathrm{CO}_{2} / 95 \%$ air humidified atmosphere. Then $100 \mu \mathrm{L}$ of the solubilization solution was added into the wells to 
lyse the cells and solubilize the formazan complex formed. The microtitre plates were maintained in a dark and humidified chamber overnight. The formation of formazan was measured with a microtitre plate reader at $550 \mathrm{~nm}$, and the percentages of cell survival were determined. The cytotoxicity was evaluated based on the percentage cell survival in a dosedependence manner relative to the negative control.

Table 1. Cytotoxicities of some selected artemisinin derivatives against HepG2 Cell Line

\begin{tabular}{lccccccc}
\hline Compounds & $\mathbf{1 1}$ & $\mathbf{1 3}$ & $\mathbf{1 4}$ & $\mathbf{1 7}$ & $\mathbf{1 9}$ & $\mathbf{2 1}$ & $\mathbf{2 2}$ \\
\hline $\mathrm{IC}_{50}(\mu \mathrm{M})$ & 37.5 & $>100$ & $>100$ & $>100$ & $>100$ & 79.9 & $>100$ \\
\hline
\end{tabular}


(III) ${ }^{1}$ H NMR Spectra

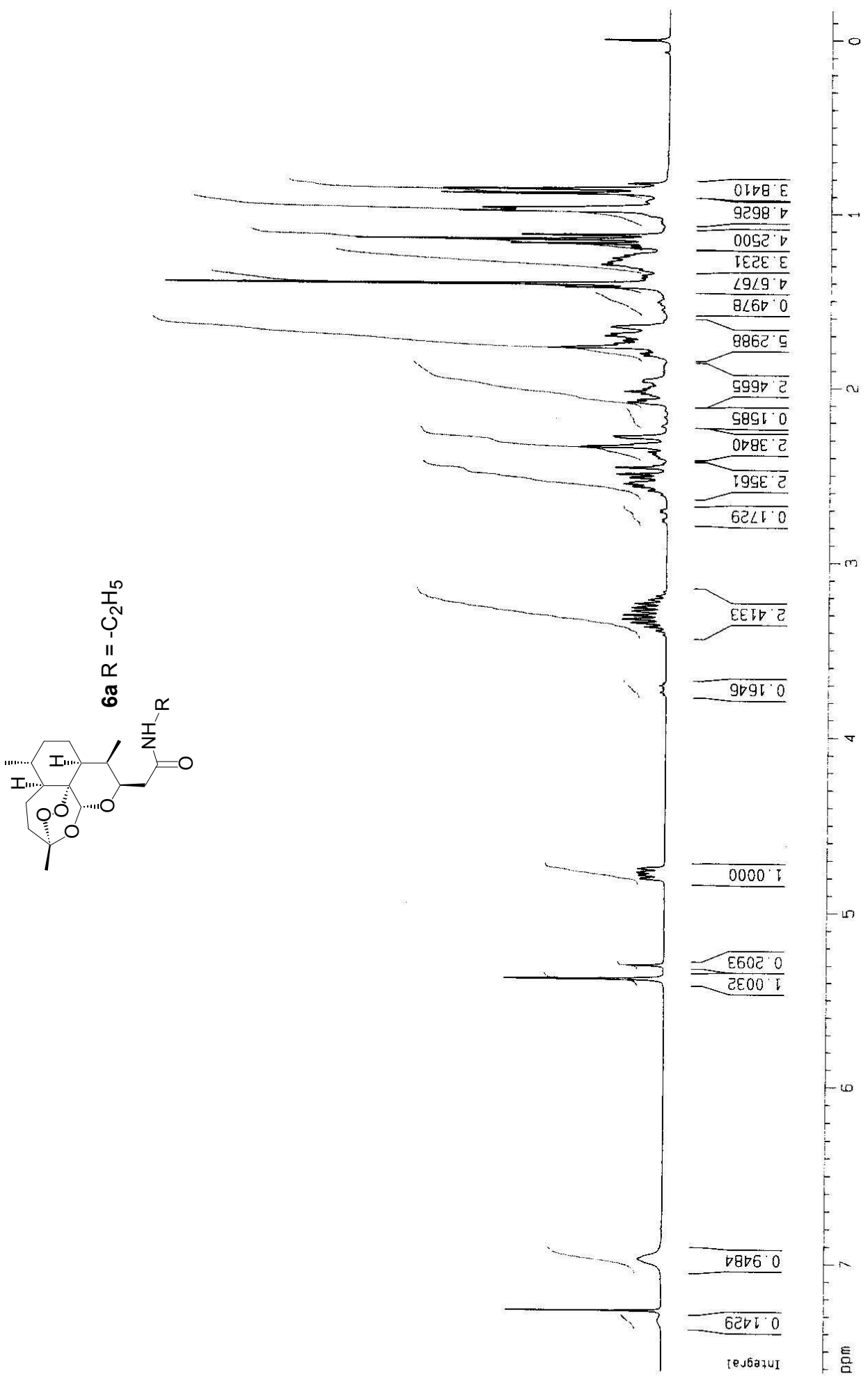




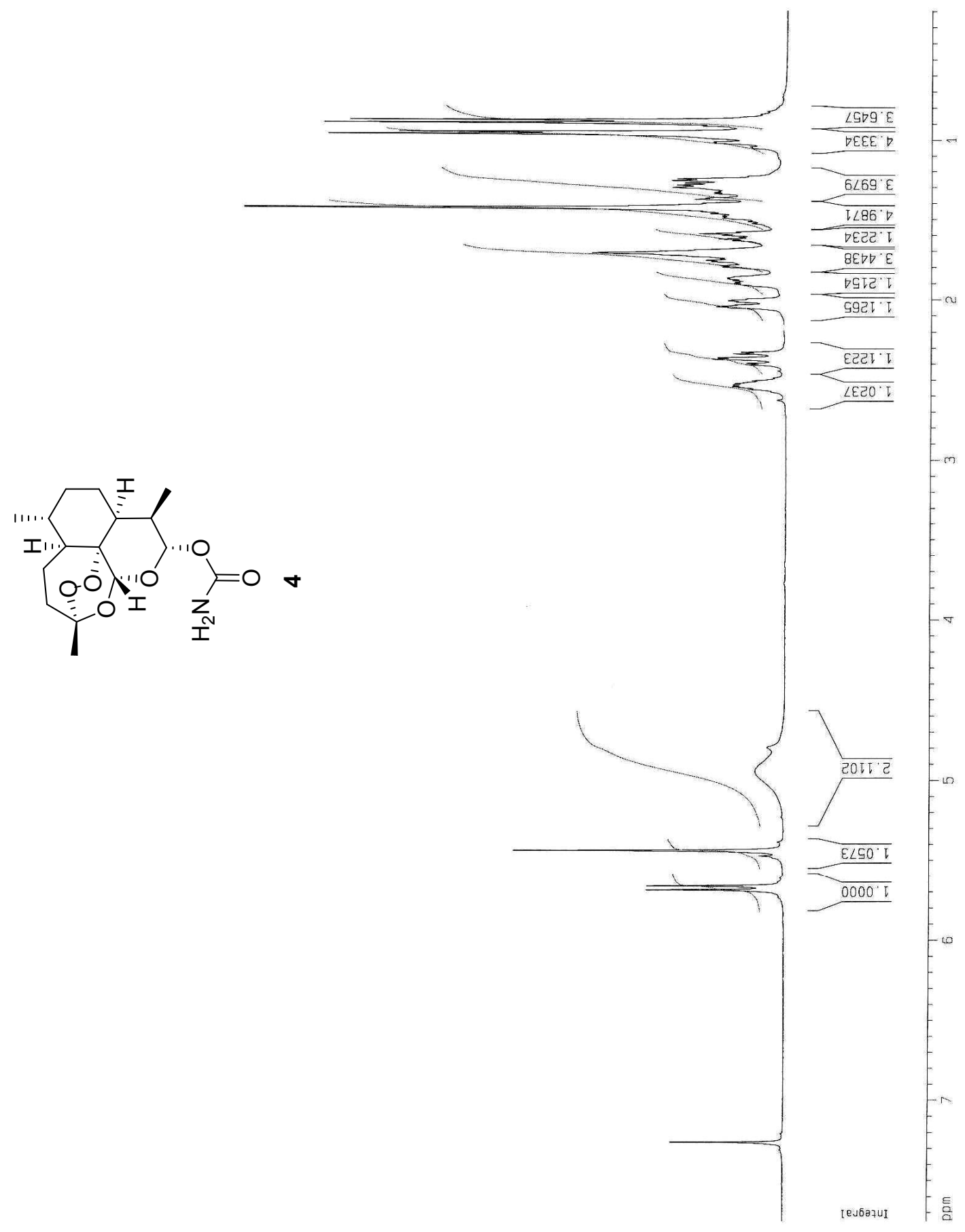




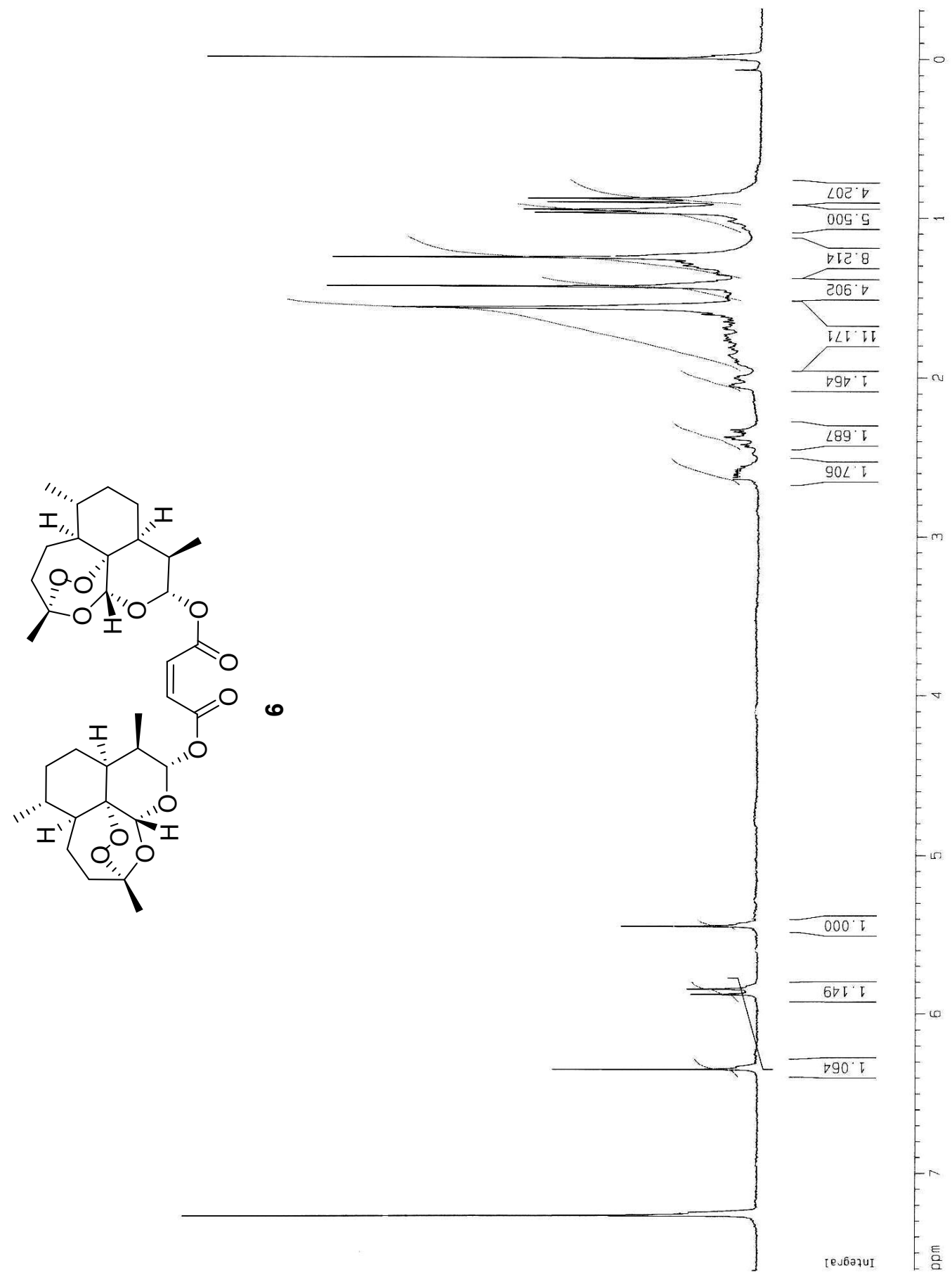




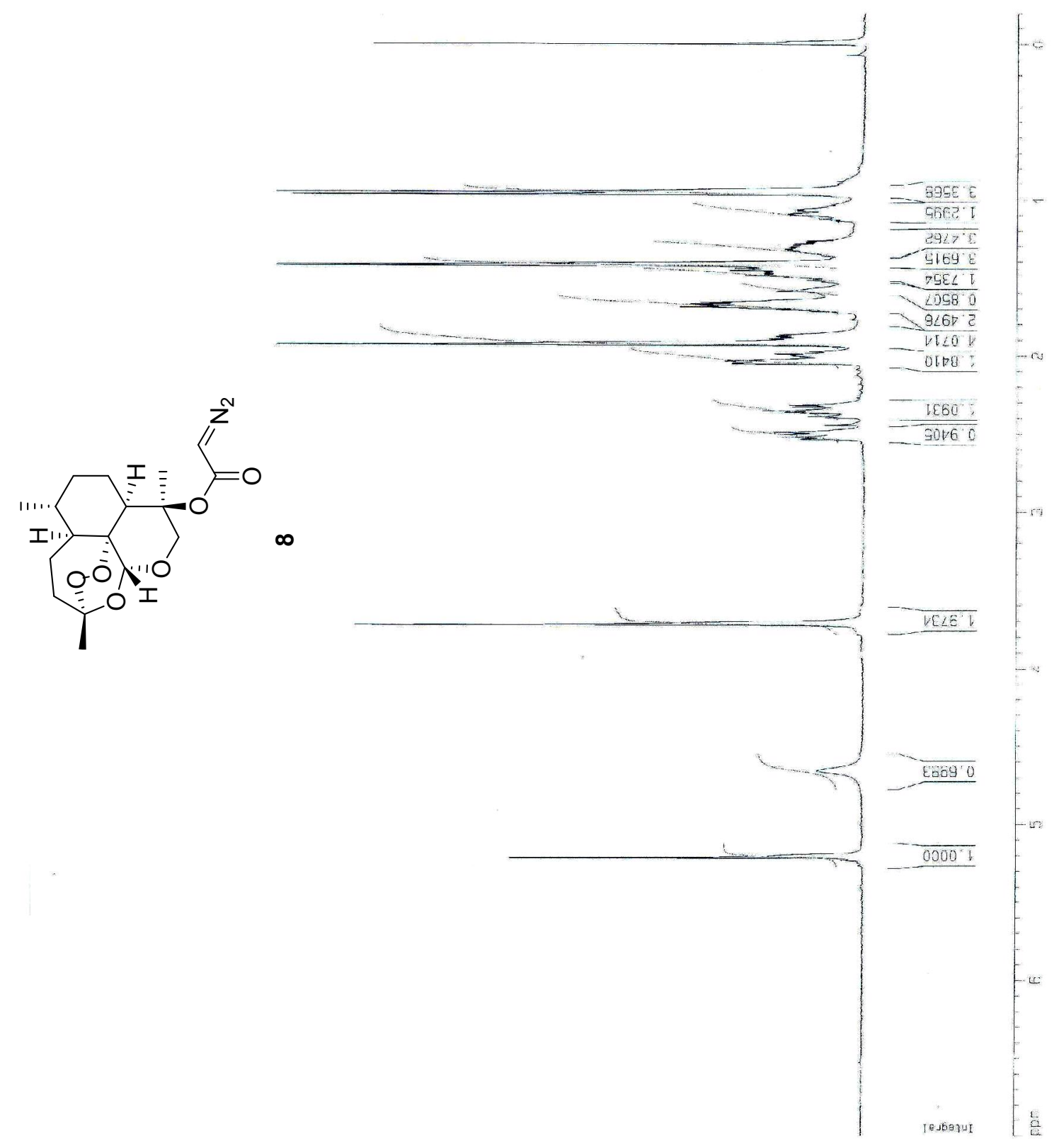




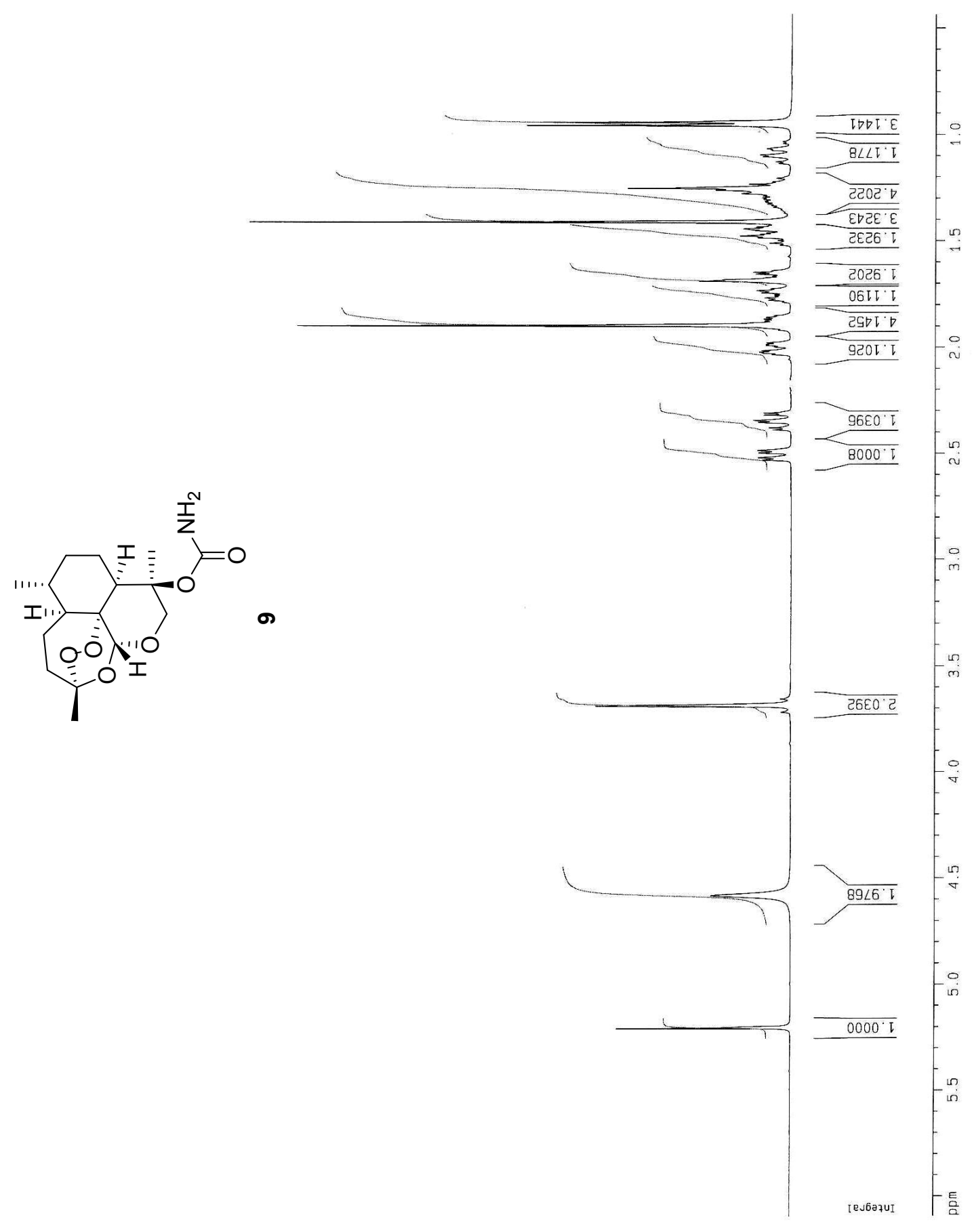




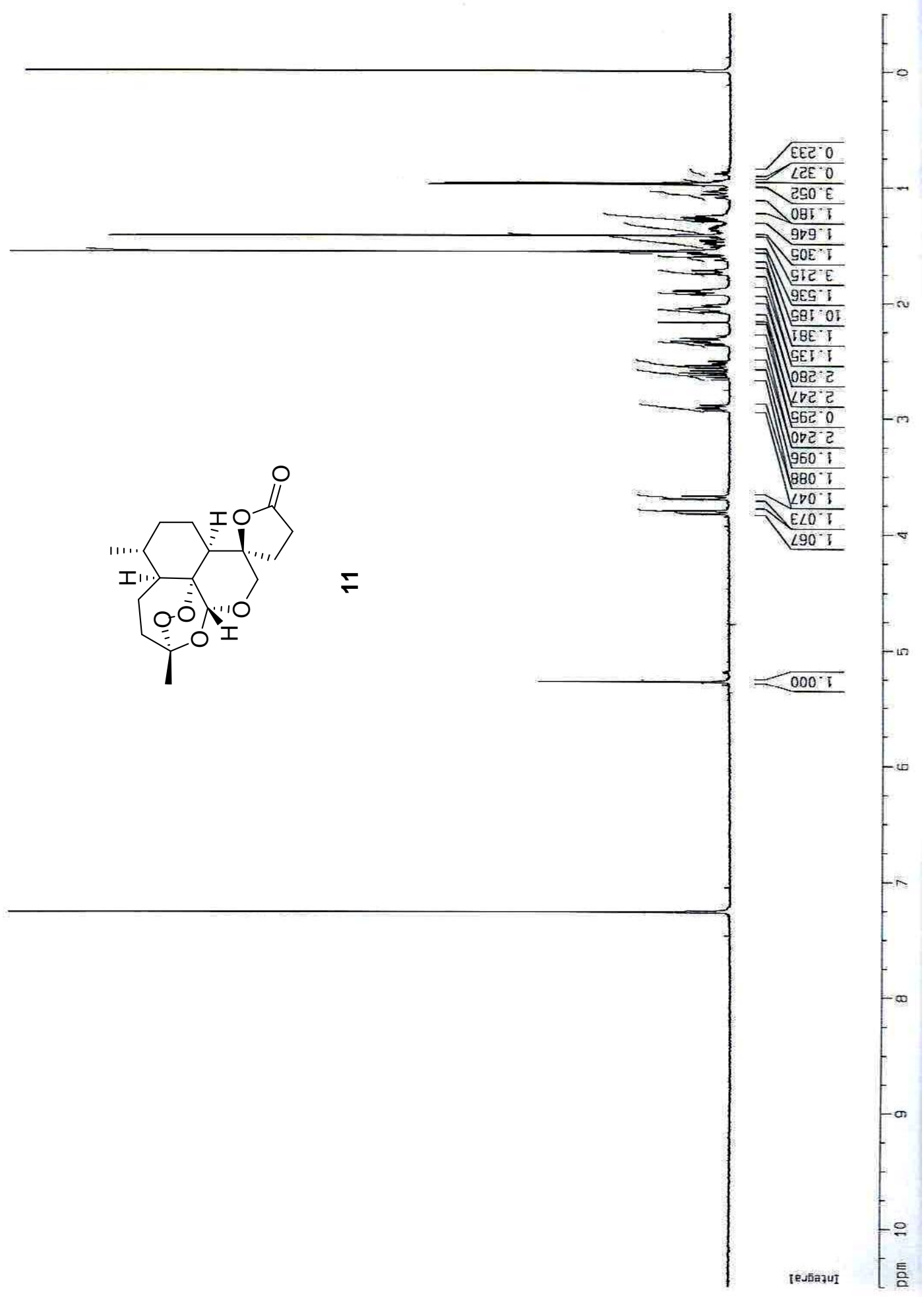



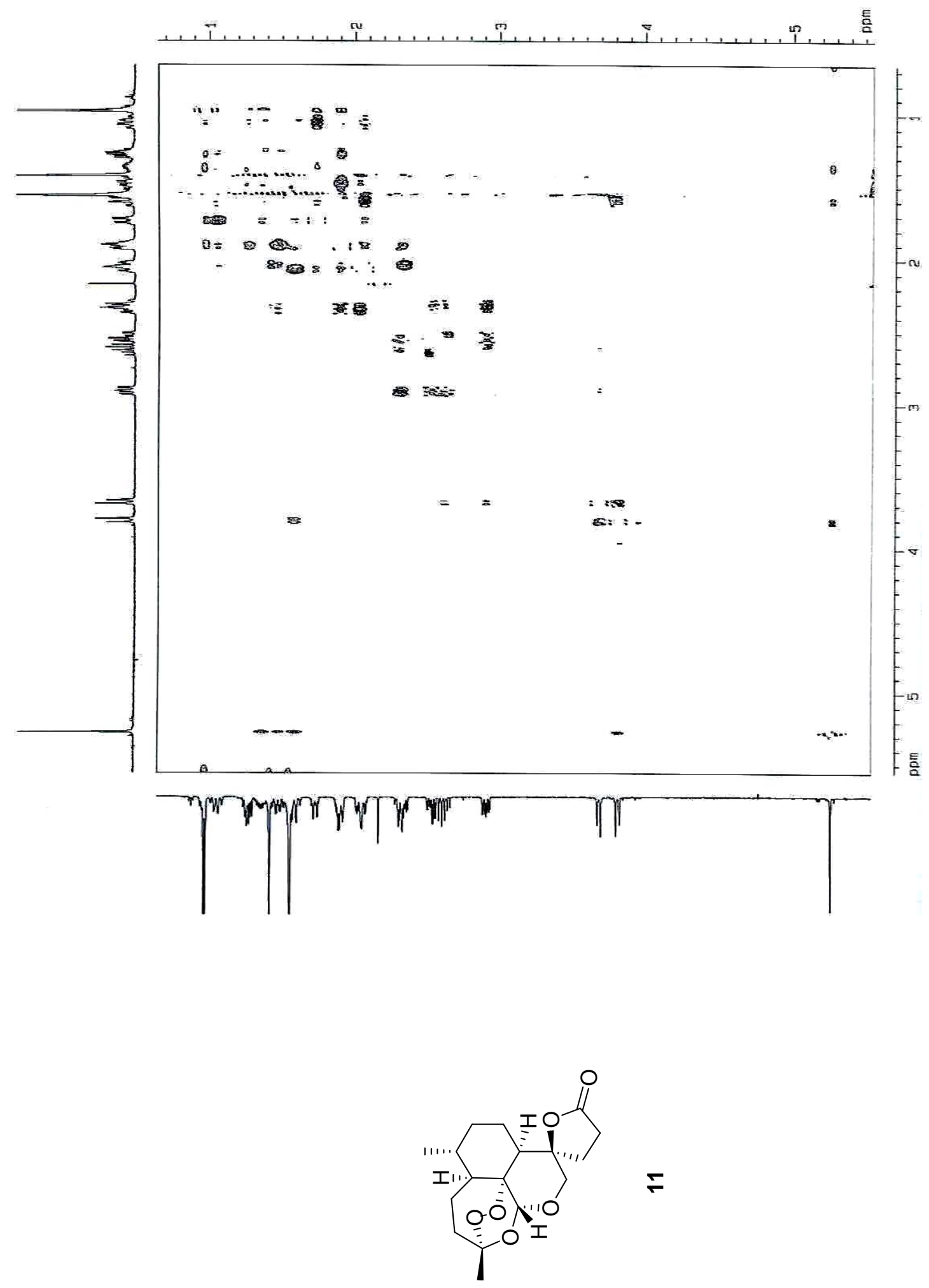


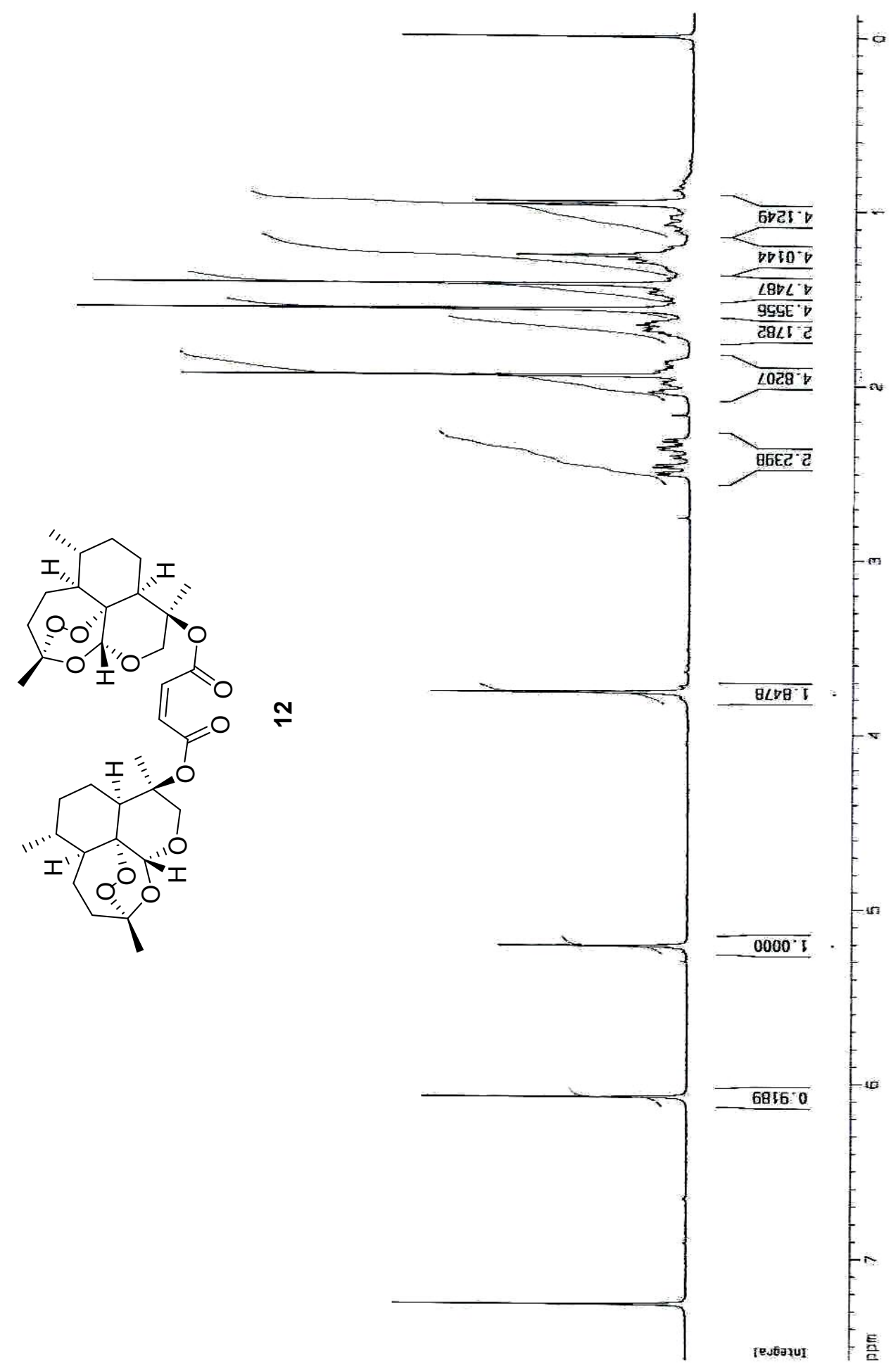




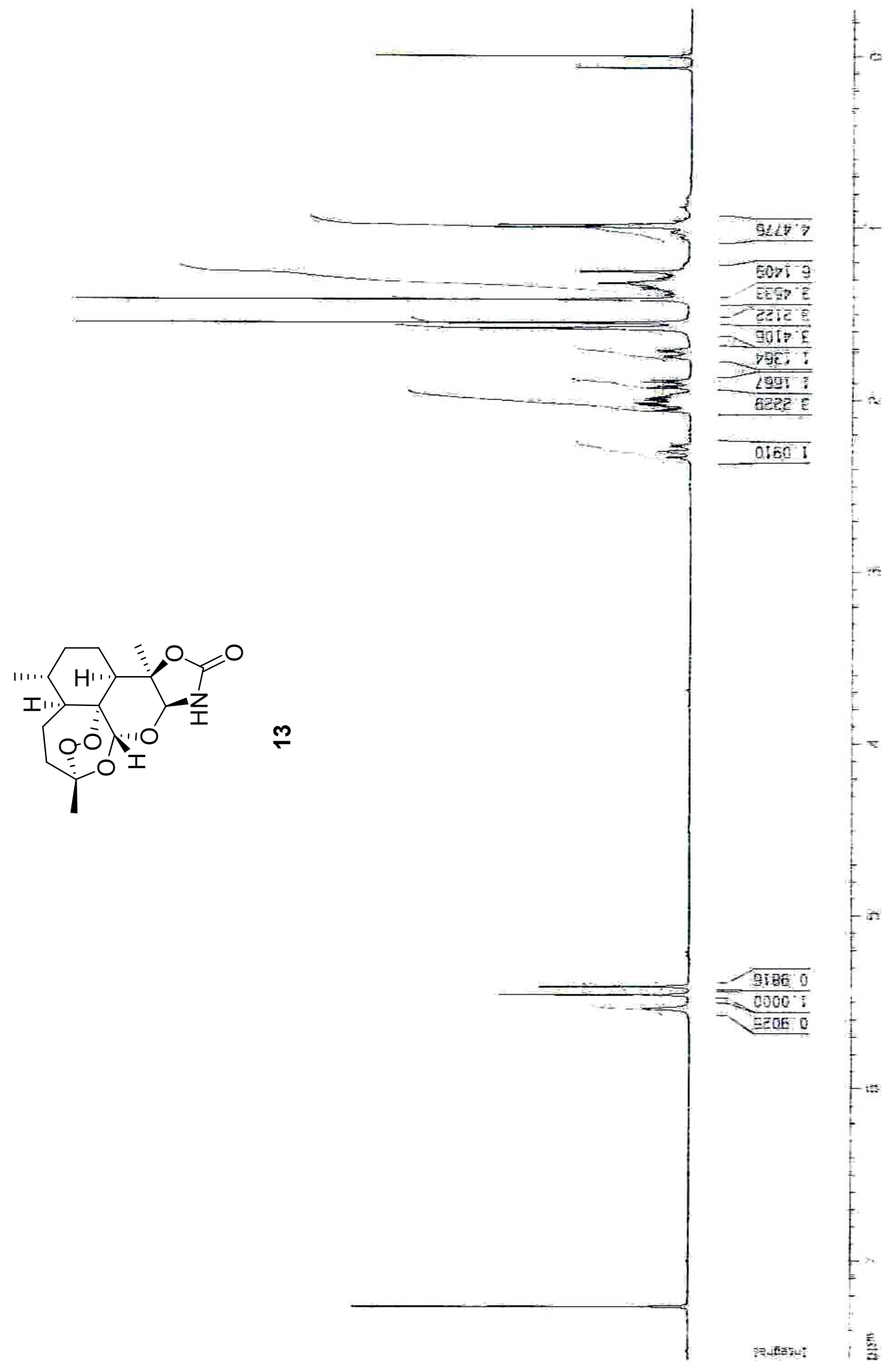



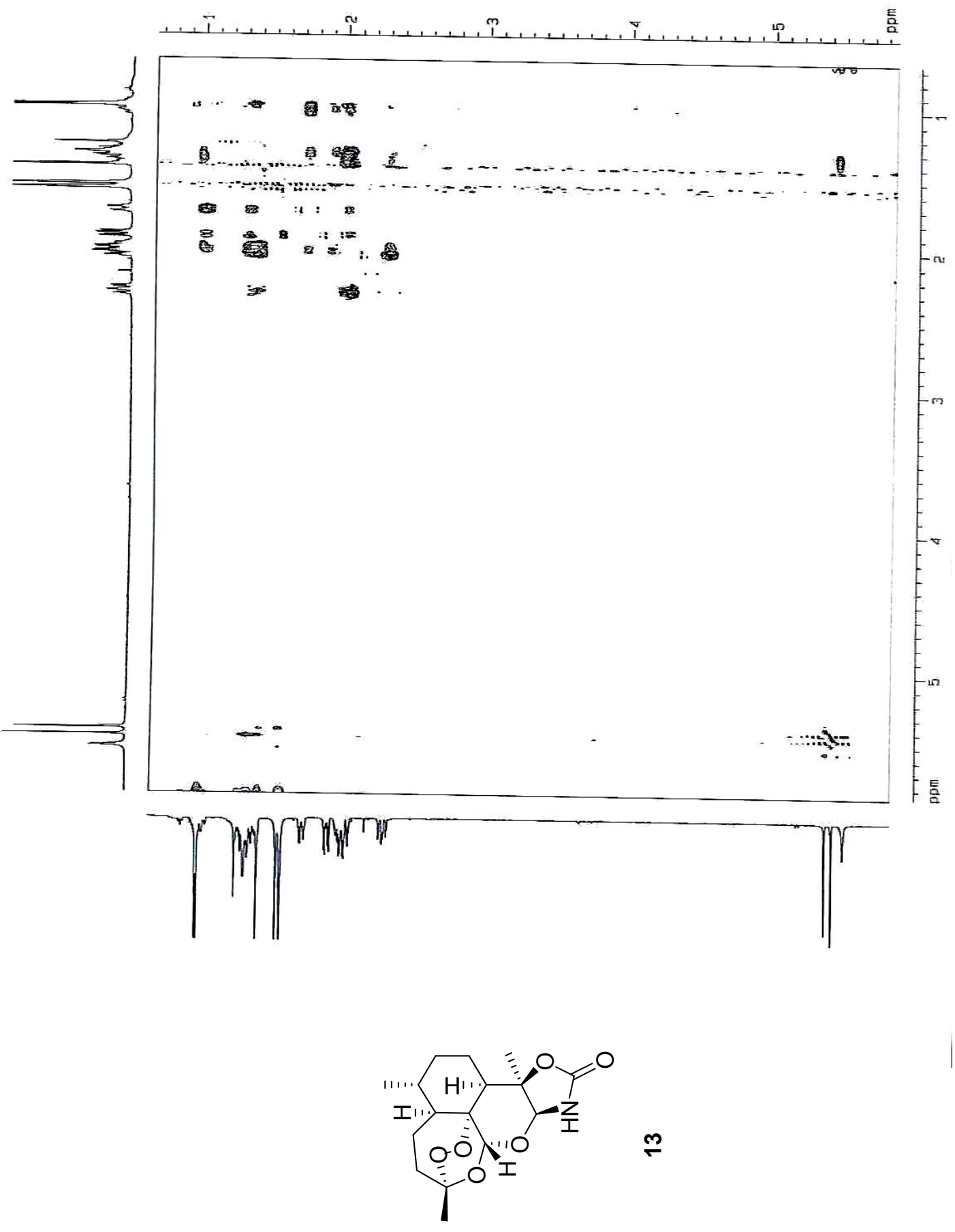


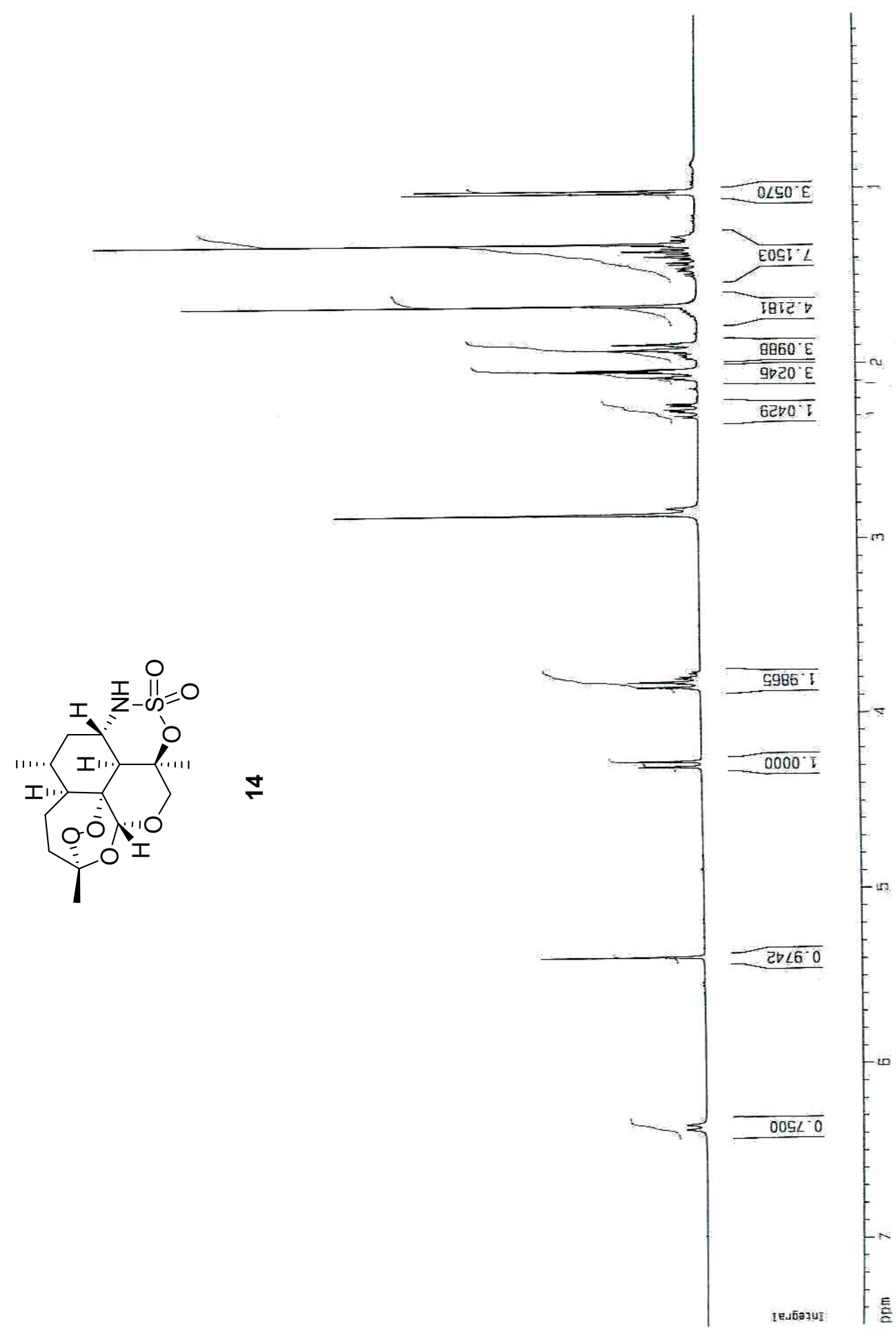




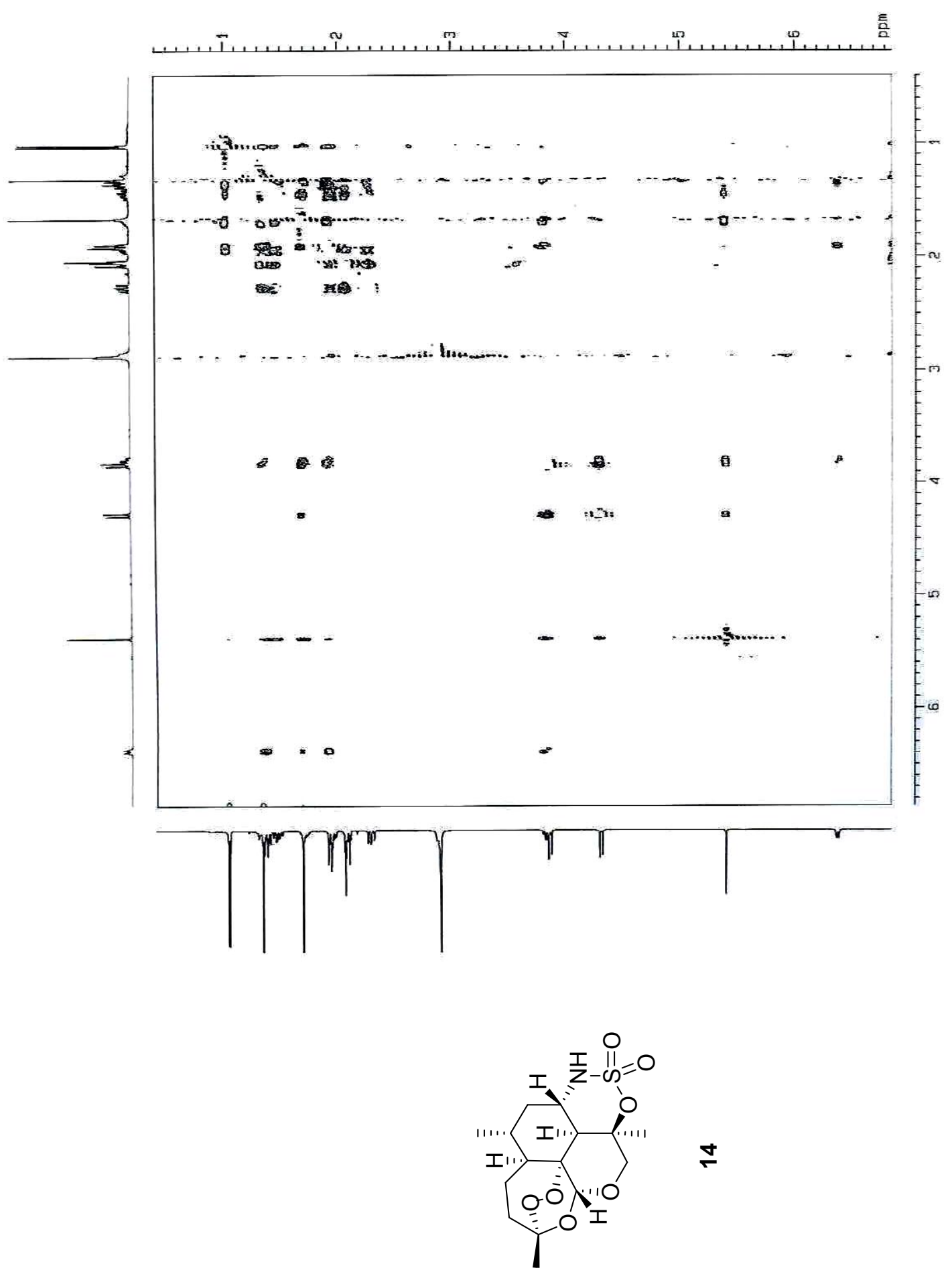




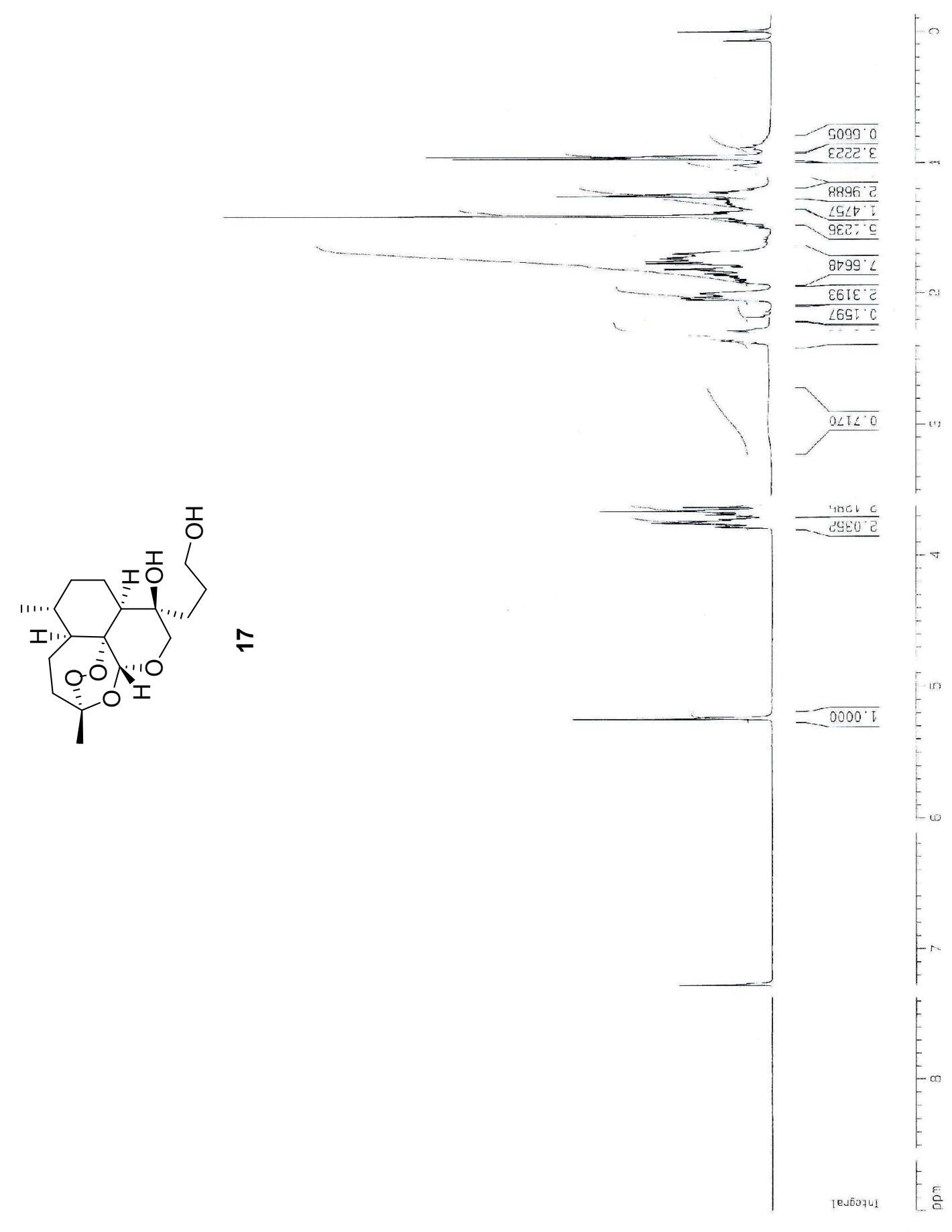




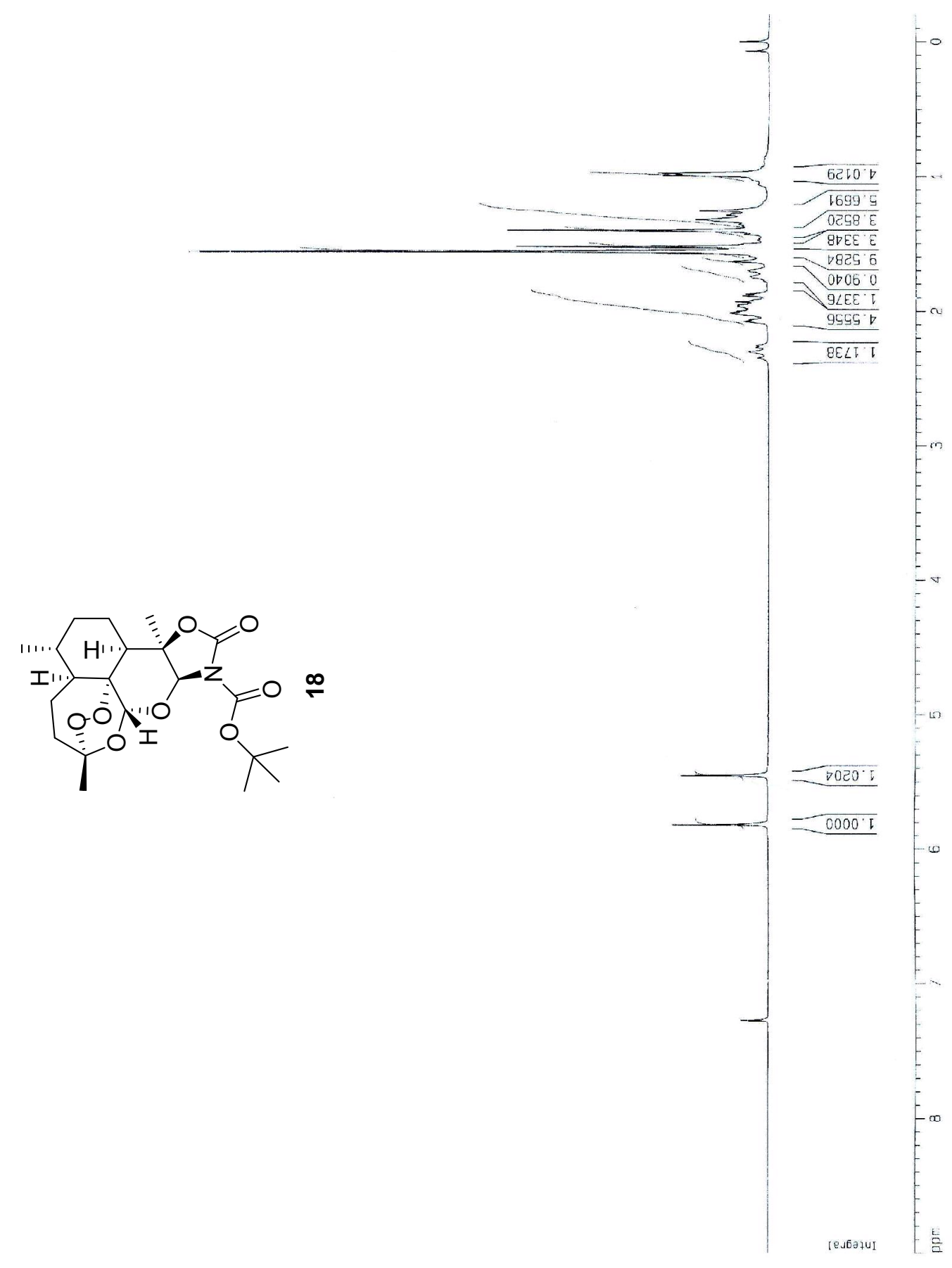




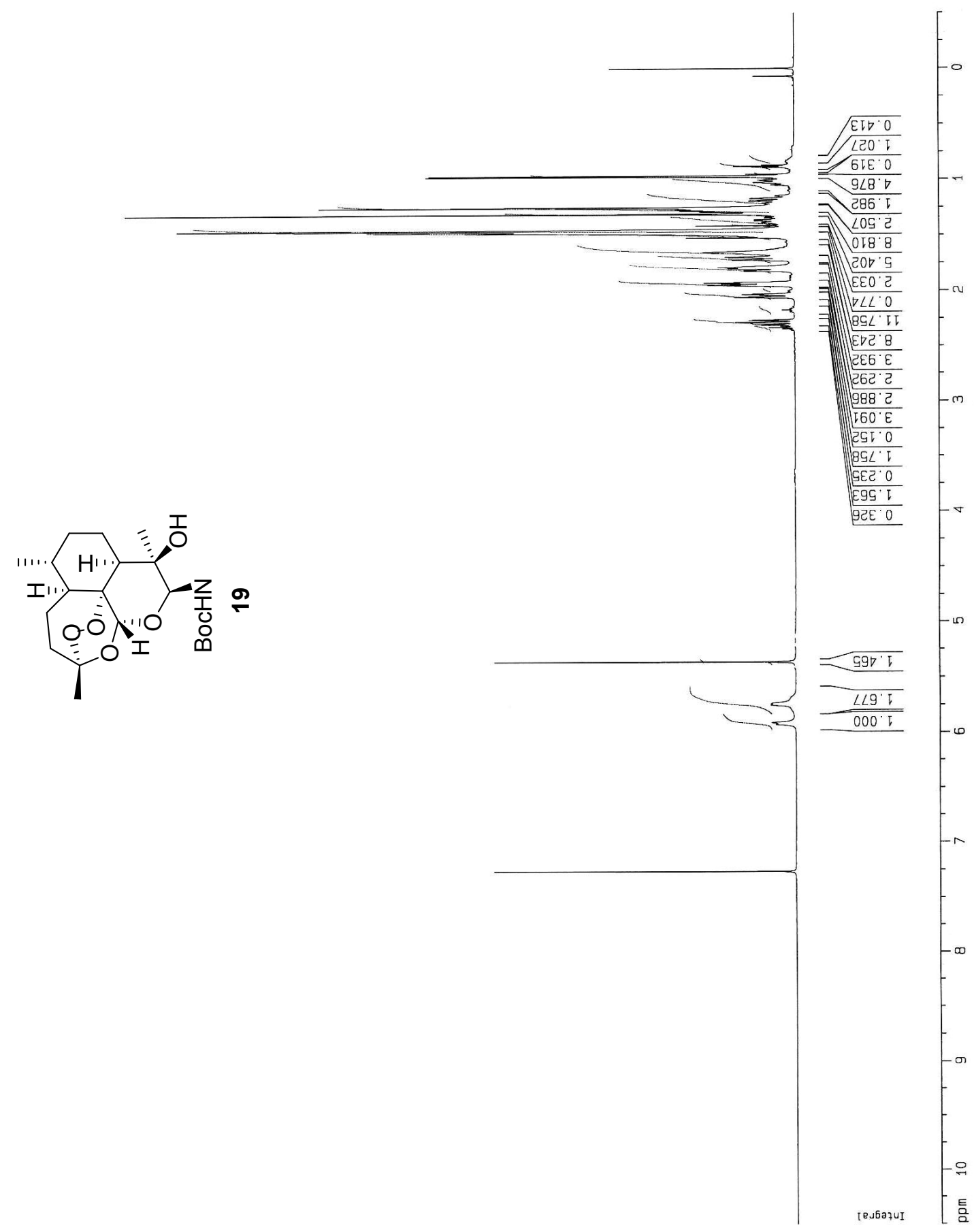




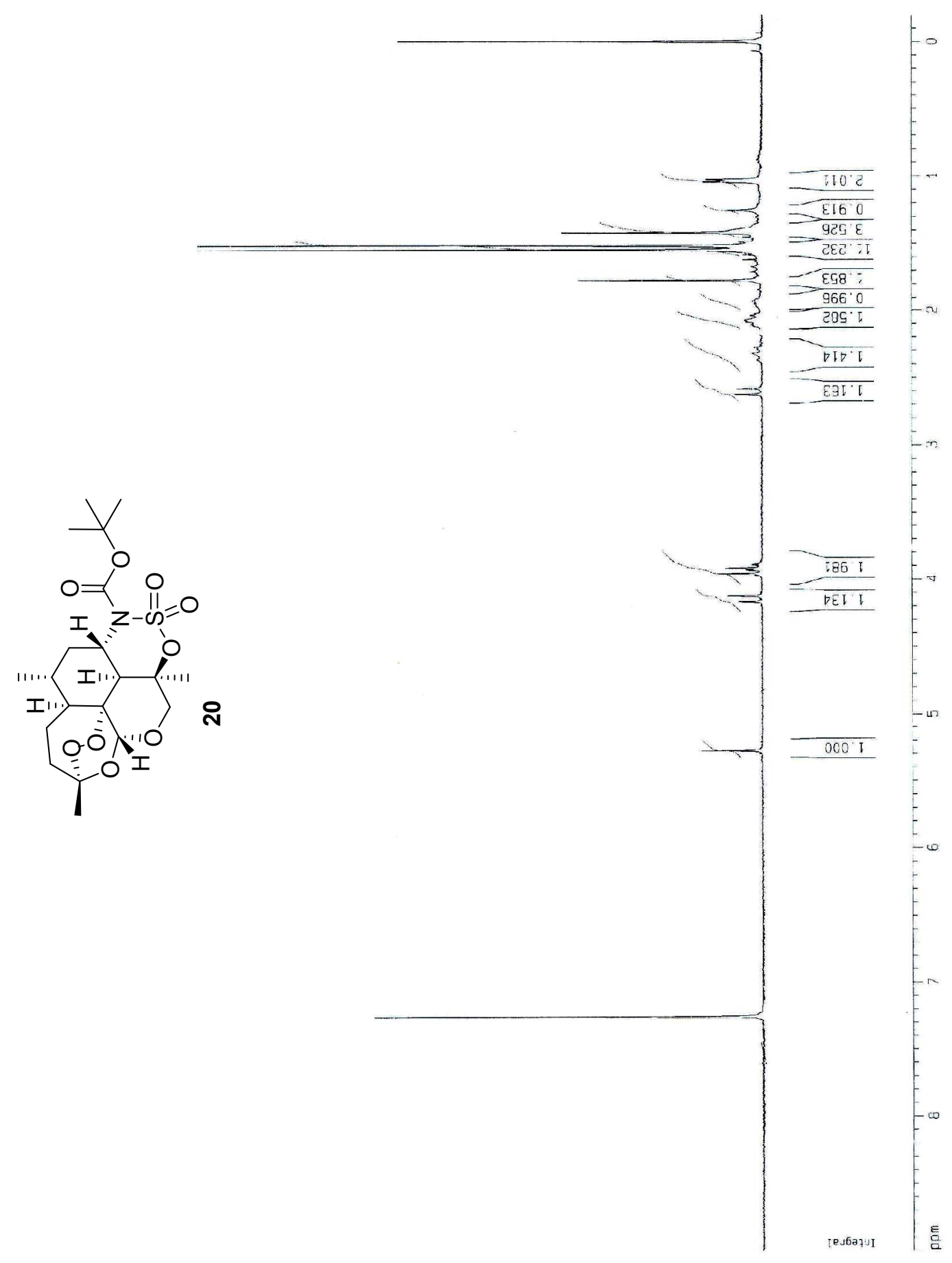




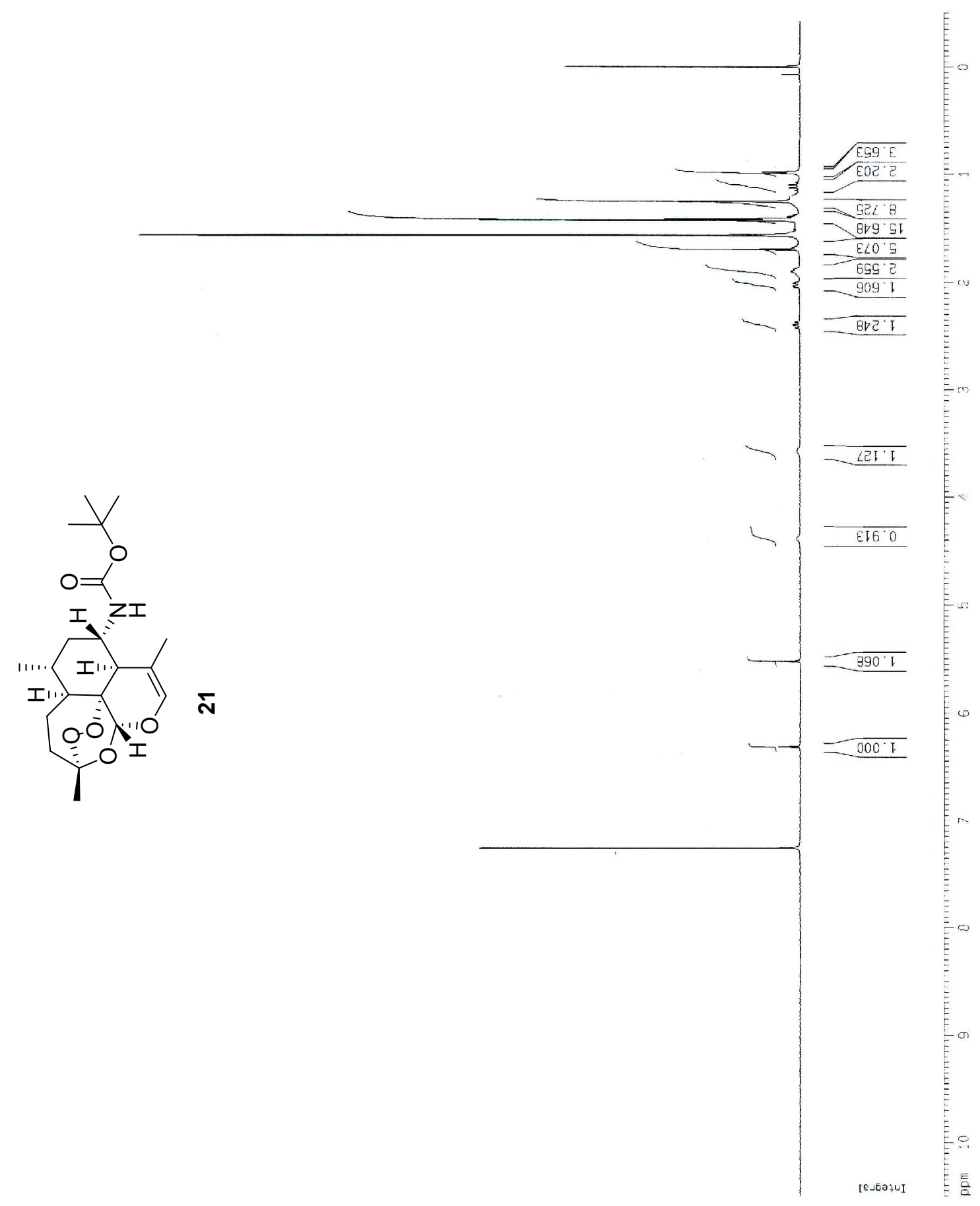




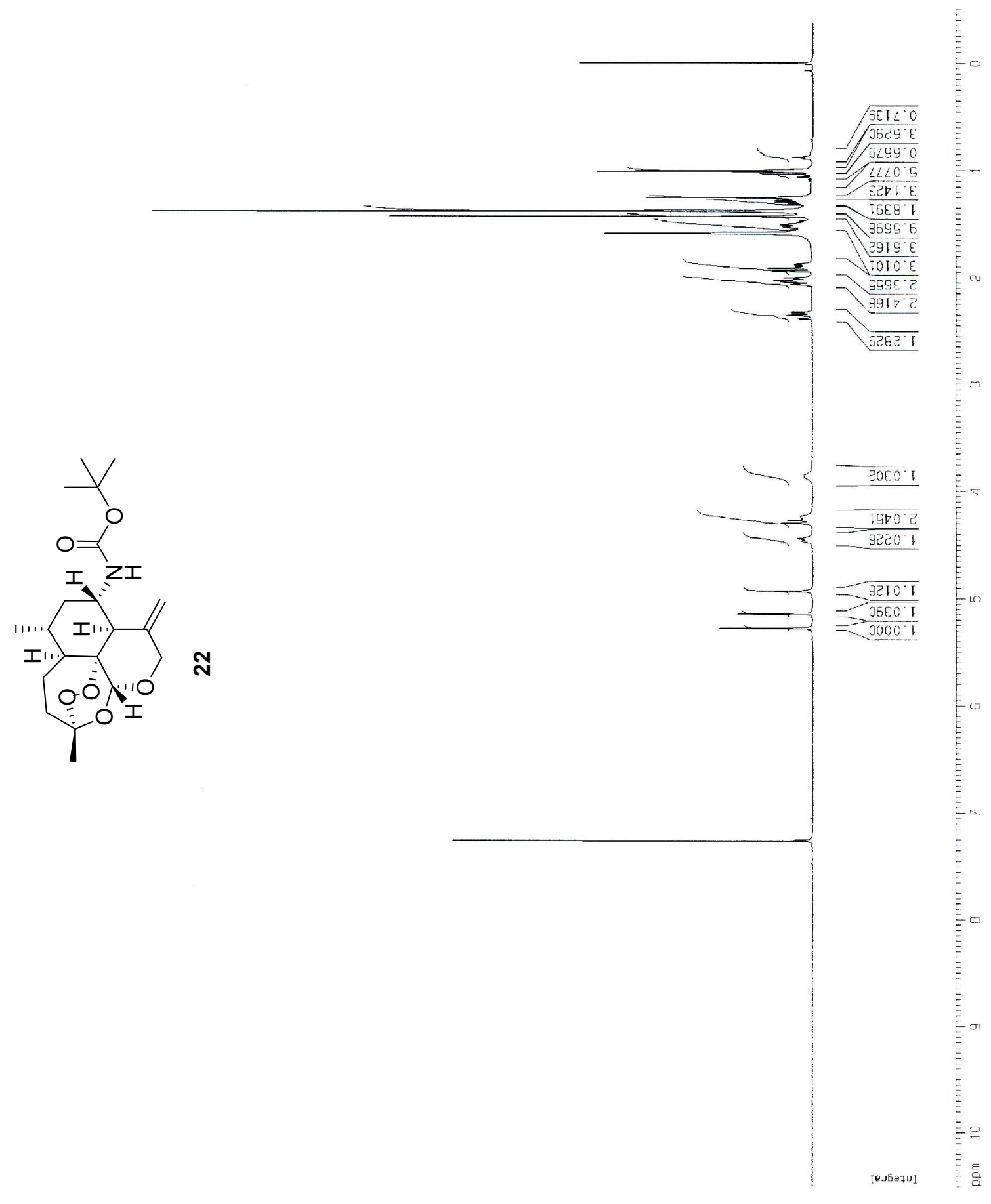

